\title{
Skylab II \\ Making a Deep Space Habitat from a Space Launch System Propellant Tank
}

\author{
Brand N. Griffin ${ }^{1}$ \\ Gray Research, Engineering, Science, and Technical Services Contract, \\ 655 Discovery Drive, Ste. 300, Huntsville, AL 35806 U.S.A. \\ David Smitherman ${ }^{2}$ \\ NASA, Marshall Spaceflght Center, Huntsville, AL 35812 U.S.A. \\ Kriss J. Kennedy ${ }^{3}$ and Larry Toups ${ }^{4}$ \\ NASA, Johnson Space Center, Houston, TX 77058 U.S.A. \\ Tracy Gill ${ }^{5}$ \\ NASA, Kennedy Space Center, Cape Canaveral, FL 32899 U.S.A. \\ and \\ A. Scott Howe ${ }^{6}$ \\ NASA, Jet Propulsion Laboratory, Pasadena, CA 91109 U.S.A.
}

\begin{abstract}
Called a "House in Space," Skylab was an innovative program that used a converted Saturn V launch vehicle propellant tank as a space station habitat. It was launched in 1973 fully equipped with provisions for three separate missions of three astronauts each. The size and lift capability of the Saturn $V$ enabled a large diameter habitat, solar telescope, multiple docking adaptor, and airlock to be placed on-orbit with a single launch. Today, the envisioned Space Launch System (SLS) offers similar size and lift capabilities that are ideally suited for a Skylab type mission. An envisioned Skylab II mission would employ the same propellant tank concept; however serve a different mission. In this case, the SLS upper stage hydrogen tank is used as a Deep Space Habitat (DSH) for NASA's planned missions to asteroids, Earth-Moon Lagrangian point and Mars.
\end{abstract}

\section{Nomenclature}

$\begin{array}{ll}C P S & =\text { Cryogenic Propulsion Stage } \\ D D T \& E & =\text { Design, Development, Test and Evaluation } \\ D S H & =\text { Deep Space Habitat } \\ E V A & =\text { Extravehicular Activity } \\ H D U & =\text { Habitation Demonstration Unit } \\ I S S & =\text { International Space Station } \\ L & =\text { Langrangian Point } \\ L E O & =\text { Low Earth Orbit } \\ M M O D & =\text { Micrometeoroid Orbital Debris } \\ M P C V & =\text { Multi Purpose Crew Vehicle } \\ S E P & =\text { Solar Electric Propulsion } \\ S L S & =\text { Space Launch System }\end{array}$

\footnotetext{
${ }^{1}$ Senior Engineer, Gray Research, Jacobs Engineering ESTS Group, Huntsville, AL, Senior Member.

${ }^{2}$ Architect, Advanced Concept Office, Mail Code ED04, Senior Member

${ }^{3}$ Engineer, Systems Architecture and Integration Office, Mail Code EA3.

${ }^{4}$ Engineer, Exploration Missions and Systems Office, Mail Code ZS1.

${ }^{5}$ Engineer, Technology Integration Office, Mail Code NE-T.

${ }^{6}$ Architect, Mission Systems Concepts, Mail Code 312E.
} 


\section{Introduction}

C KYLAB was sold on the economy of using Apollo Program parts. There had been a tremendous investment in the development of hardware that took men to the Moon but these missions came to an end leaving important, unanswered questions about future human spaceflight. Skylab was a cost-effective solution that used Apollo elements for a low Earth orbit (LEO) space station to address these questions, in particular the effects of long-term weightlessness on humans. The project was possible because of the heavy lift capability of the Saturn V launch vehicle and the availability of a third stage hydrogen propellant tank. In one launch, the Saturn V placed the entire Skylab space station plus consumables for three missions of three astronauts each. In contrast, the International Space Station (ISS) has taken 10 years to assemble requiring more than

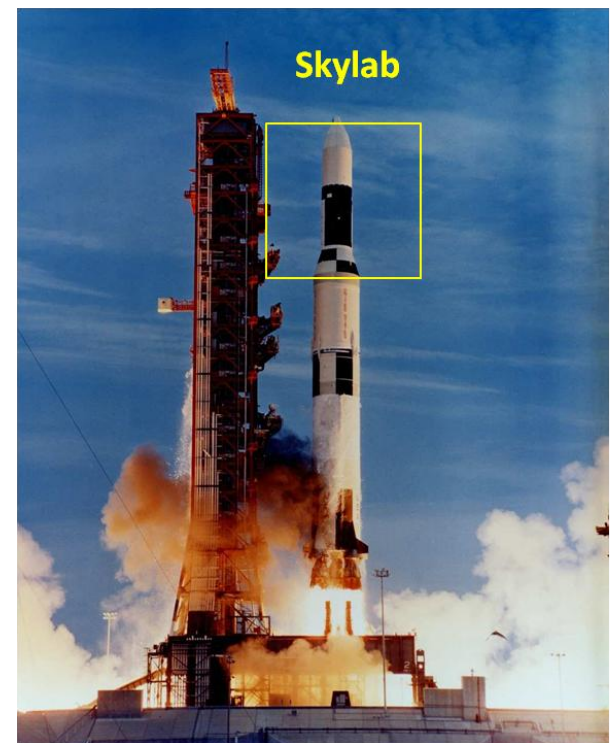

Saturn V

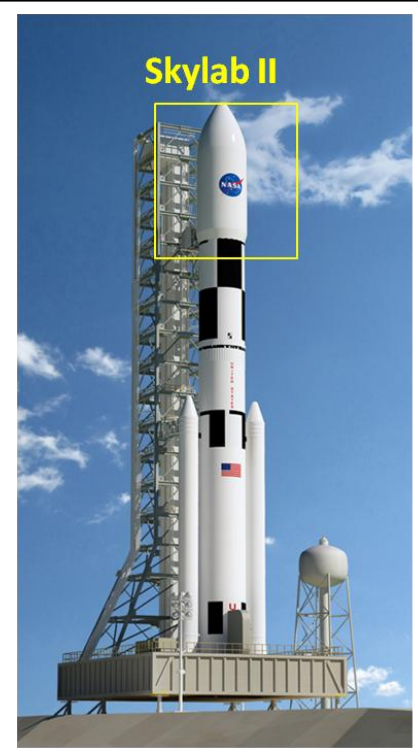

Space Launch System

Figure 1. Propellant Tanks Used for Space Habitats. (NASA images)

115 space flights using five different types of launch vehicles ${ }^{1}$. Today, NASA is developing the Space Launch System that offers Saturn-like lift for even larger diameter payloads. This, combined with NASA's goal of human spaceflight beyond LEO makes a Skylab II type solution very attractive for the Deep Space Habitat (DSH). Figure 1 shows the Saturn V Skylab launch (left) and a proposed configuration for the Space Launch System (right).

\section{The Skylab Model}

\section{A. Single Launch}

The Skylab approach is a compelling option because it enables an integrated and fully provisioned Deep Space

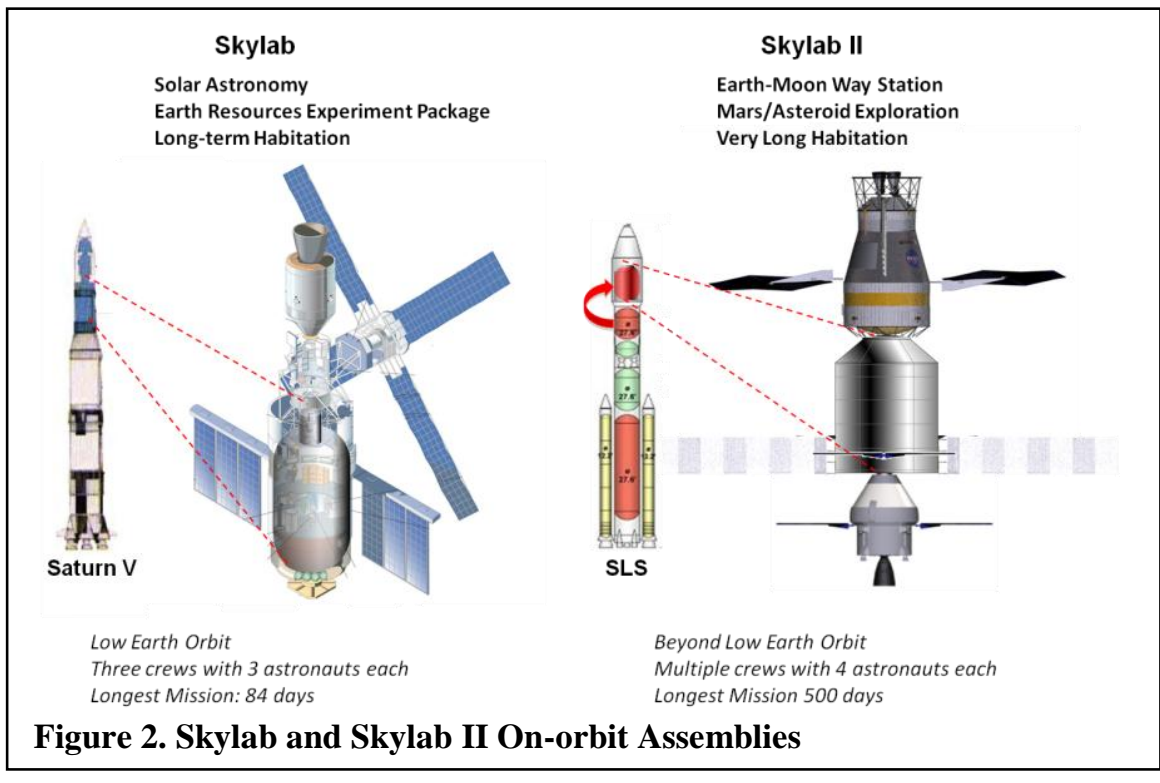

Habitat to be delivered to orbit in a single launch. The benefits of a single launch are lower cost and the habitat can be assembled and checked out on the ground using trained technicians rather than having multiple launches with on-

\footnotetext{
${ }^{1}$ International Space Station, NASA Fact and Figures, Page Editor: Amiko Kauderer, NASA Official: Brian Dunbar, Page Last Updated: September 20, 2011
} 


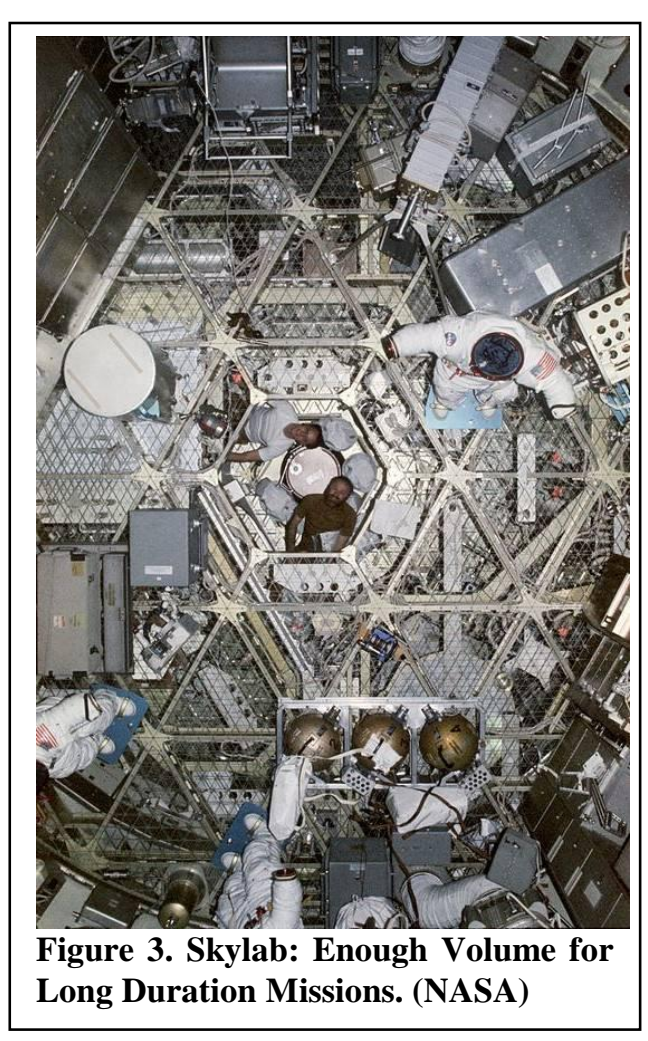

orbit assembly, integration and checkout by astronauts in the weightless environment. Figure 2 shows a comparison of the onorbit assemblies of Skylab and a Skylab II concept.

Recent studies estimate the mass for the 500 day DSH outfitting to be approximately $31,000 \mathrm{~kg}(68,400 \mathrm{lbm})$. This is $1,500 \mathrm{~kg}$ $(3,307 \mathrm{lbm})$ less than the hydrogen mass the SLS tank is designed to carry. Different configurations of the SLS system can launch payloads of $70 \mathrm{mt}, 95 \mathrm{mt}$, and $140 \mathrm{mt}$. This means, at a minimum, the completely integrated DSH could be delivered to LEO in one launch using the configuration with the least payload capability.

\section{B. Qualified Structure}

A big advantage of using a propellant tank is that the structure is already designed to take the vehicle launch loads and with the SLS hydrogen tank, it is sized for an internal pressure of $345 \mathrm{kPa}(50$ psia), which is over 3 times the highest habitat atmospheric pressure requirement.

\section{Habitable Volume}

Another important advantage of the Skylab model is livable volume. It has always been a challenge providing adequate habitable volume for astronauts. The Saturn V propellant tank used

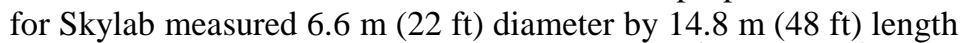
yielding an internal pressurized volume of $360 \mathrm{~m}^{3}\left(12,713 \mathrm{ft}^{3}\right)$. The result was a spacious $120 \mathrm{~m}^{3}\left(4238 \mathrm{ft}^{3}\right)$ per crew member (See Fig. 3 ). Taking into account the subsystems and outfitting, the habitable volume was $283 \mathrm{~m}^{3}\left(10,000 \mathrm{ft}^{3}\right)$ or $94 \mathrm{~m}^{3}\left(3,320 \mathrm{ft}^{3}\right)$ per crew member. Habitable volume has been studied well before the first human spaceflight and, because of many subjective factors, continues to be studied. The curves that compare mission duration to crew volume tend to discount Skylab as an anomaly because it provided too much volume. For deep space missions, this is an anomaly the crew can live with. Using the SLS hydrogen tank for Skylab II provides a volume-friendly solution for long duration missions beyond LEO. The tank is $8.5 \mathrm{~m}(27.8 \mathrm{ft})$ in diameter and $11.2 \mathrm{~m}(36.7 \mathrm{ft})$ long totaling $495 \mathrm{~m}^{3}\left(17,481 \mathrm{ft}^{3}\right)$ in volume (Figure 4). This provides a similar Skylab ratio of $123 \mathrm{~m}^{3}\left(4344 \mathrm{ft}^{3}\right)$ per crew member. Assuming a conservative $1 / 3$ of the volume is used for subsystems and outfitting the remaining volume provides a habitable volume of $82 \mathrm{~m}^{3}\left(2896 \mathrm{ft}^{3}\right)$ per astronaut. Even if only half the volume is habitable, the ratio would be $61 \mathrm{~m}^{3}\left(2154 \mathrm{ft}^{3}\right)$ per crew member. In either case, the volume per crew far

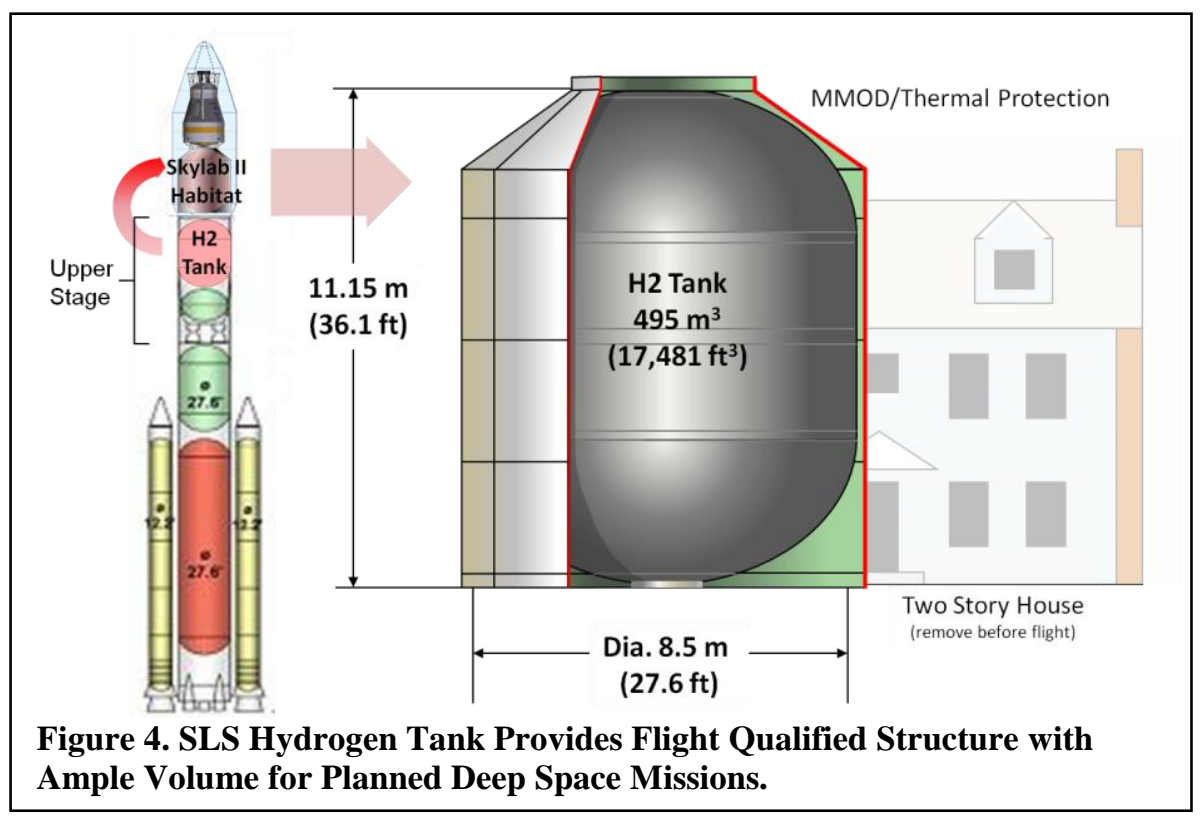
exceeds the NASA Std 3000 optimal recommendation of $25 \mathrm{~m}^{3}\left(883 \mathrm{ft}^{3}\right)$. In addition to volume, the tank aspect ratio is conducive for habitat internal configuration. The length accommodates three or four transverse floors and the diameter is sufficient for crew translation and the outfitting of crew systems. The tank ring frames and stringers provide convenient attach points for floors and equipment. Furthermore, the dimensions allow for proper functional adjacency including separation of noisy and quite activities.

\section{Low Risk Option}




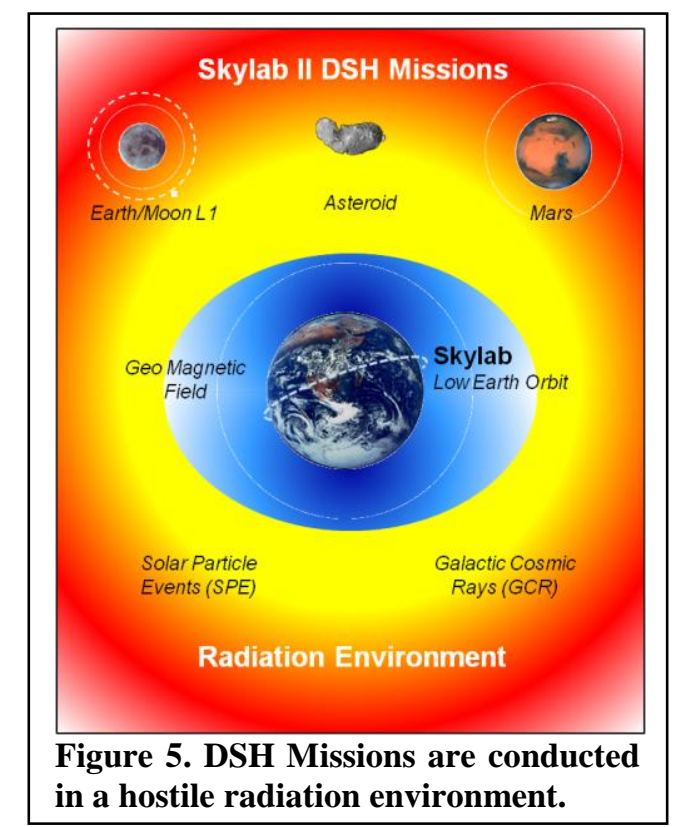

There are many configurations for a DSH, but the three prominent options are ISS-derived, new design and Skylab II. The ISS-derived solution uses the structural test article for the US Lab. Because it was designed for a Shuttle launch, it would need to be analyzed and modified to fly on an expendable launch vehicle and currently, no US shroud is large enough to accommodate this module. Historically, new designs are expensive because of the initial system definition leading to design, development, test, and evaluation (DDT\&E). In contrast, a SLS flight-ready pressure vessel is the low cost risk option because it does not pay for the DDT\&E. Like Skylab, the launch vehicle program has paid for the non-recurring cost. The schedule risk is reduced because the largest element of the habitat is purchased off the production line rather than made as a unique pressure vessel. This reduces the tooling and offers program start flexibility as compared to a cleansheet approach.

\section{E. Operating Environment}

Compared to the original Skylab mission, Skylab II operates in a more challenging space environment, has longer missions, and a larger crew size. These missions are sized for a crew of four astronauts with durations up to 500 days.

Skylab's environment was in low Earth orbit (LEO) at an inclination of 50 degrees and altitude of $440 \mathrm{~km}$ (250 $\mathrm{mi}$ ). The habitat included micrometeoroid protection, but because it was located below the Earth's geomagnetic field, Skylab did not have dedicated radiation protection. Skylab II missions are both long duration and beyond LEO; therefore, astronauts must have protection from both Solar Particle Events and Galactic Cosmic Rays (Figure 5). Radiation protection is a serious and complex subject involving physics and physiology; blood forming organs and bremsstrahlung. Protection from the somewhat random and episodic SPEs is typically handled by storm shelters with the equivalent of spherical shielding. Given the alarm, the crew retreats to a sheltered area (often crew quarters) until the event is over and radiation levels are acceptable. These storms may last a few days, however the

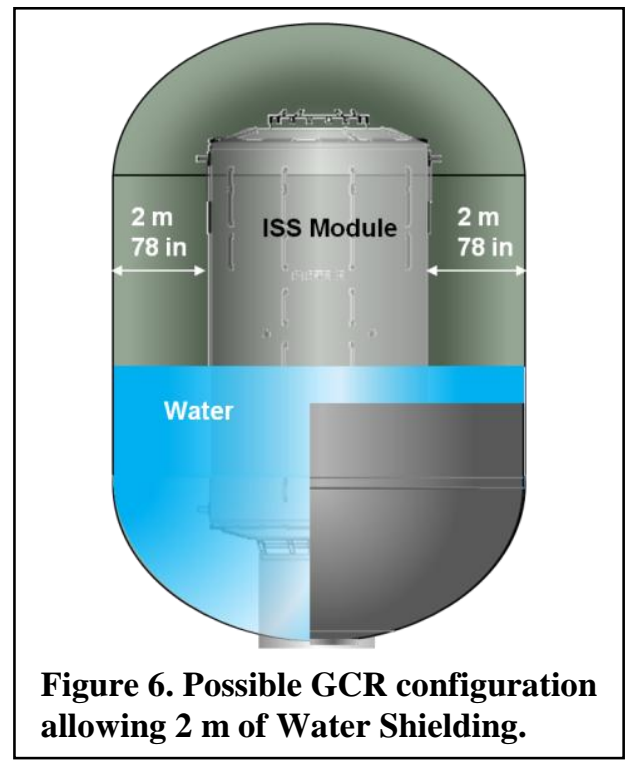

crew is able to leave the shelter for short periods without lethal consequences. The solution for GCR is more elusive. In essence the protection should have the equivalent effectiveness of the Earth's atmosphere. Like all radiation, the effects are time-dependent and because the deep space missions are long duration, the protection must be continuous and omnidirectional. This requires either a lot of power or a lot of mass or both. Experts disagree, but some have suggested a couple of meters of water may do the trick. If this is the case, then a possible solution is to place an ISS US Lab size module within the Skylab II leaving approximately 2 meters between shells (Figure 6). If the void were filled with water the mass of water alone would be $389 \mathrm{mt}$. For water mass only, this would take 4-5 launches using the $95 \mathrm{mt}$ SLS.

Another difference is the thermal environment. In LEO, Skylab was influenced by its proximity to the Earth and cycling in an out of the shadow on every orbit. The DSH missions operate in a colder environment yet are exposed to constant sunlight. This has implications on the view angles of radiators and solar arrays as well as the energy storage requirements.

\section{F. Configuration}

Skylab launched with a habitable workshop, telescope, airlock, and all provisions for three crews to operate a total of 171 days on orbit. The Apollo Command Module was used to ferry astronauts between the Earth's surface and the workshop. Skylab II is similar only a little more ambitious. The similar part is that crews will use an Apollo-like Multi Purpose Crew Vehicle (MPCV) for Earth transfer. The ambitious part comes with more elements, additional transfer vehicles, and longer missions (Figure 7). It is assumed that the DSH will be based at Earth-Moon 


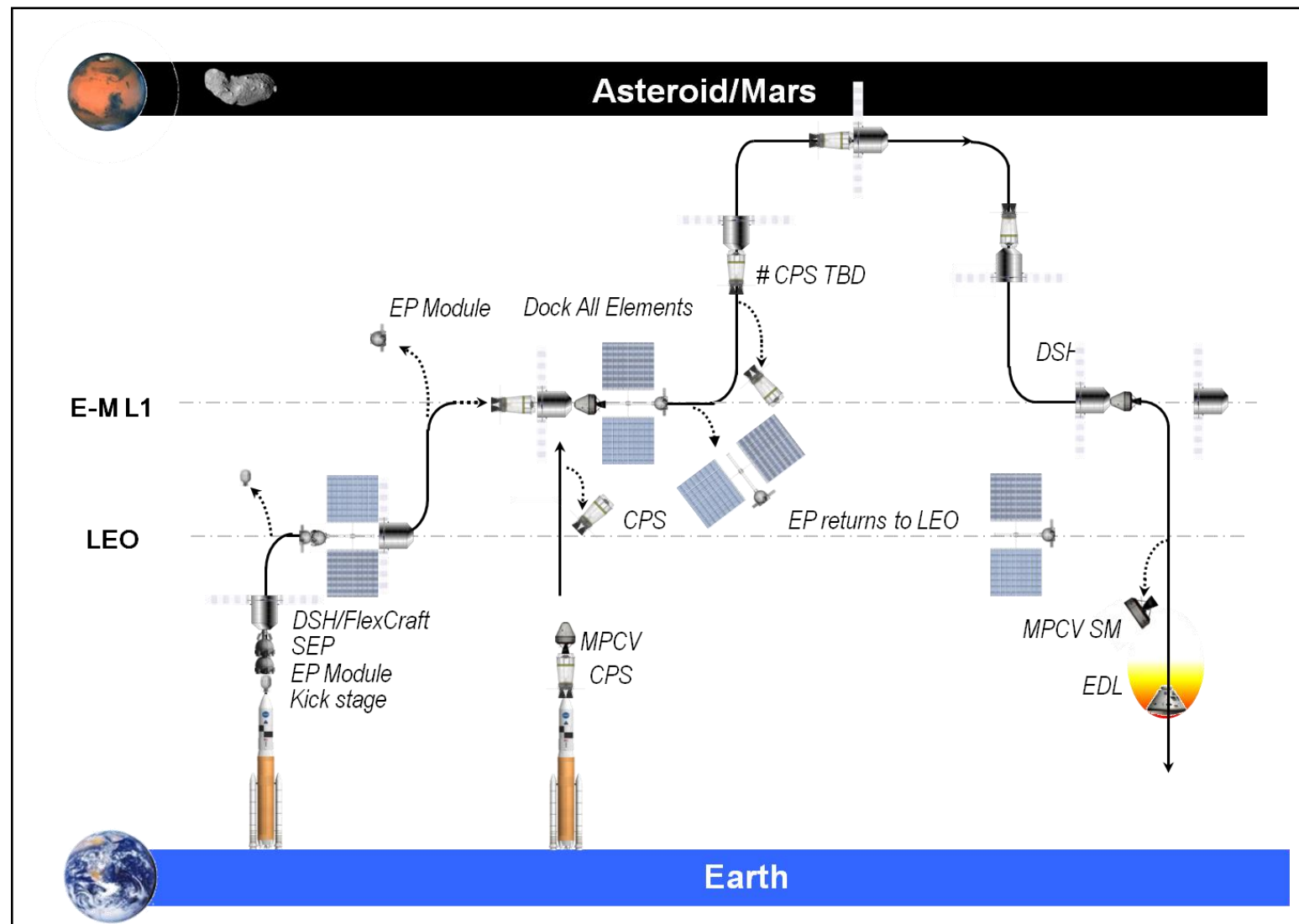

Figure 7. Candidate Mission Architecture for a Reusable DSH Based at Earth-Moon L1.

L1 or L2 rather than have repeated exposure to radiation while passing in and out of the van Allen belts. A Solar Electric Propulsion (SEP) stage will be used to transfer the pre-provisioned Skylab II from LEO to the Lagrangian point. This same stage will return to LEO then be used to transfer cargo between as needed. For an asteroid or Mars mission, chemical propulsion stages will be delivered and mated to the DSH. Later, the crew in the MPCV will launch and rendezvous with the assembly for checkout prior to departure. There are two options for the return. One

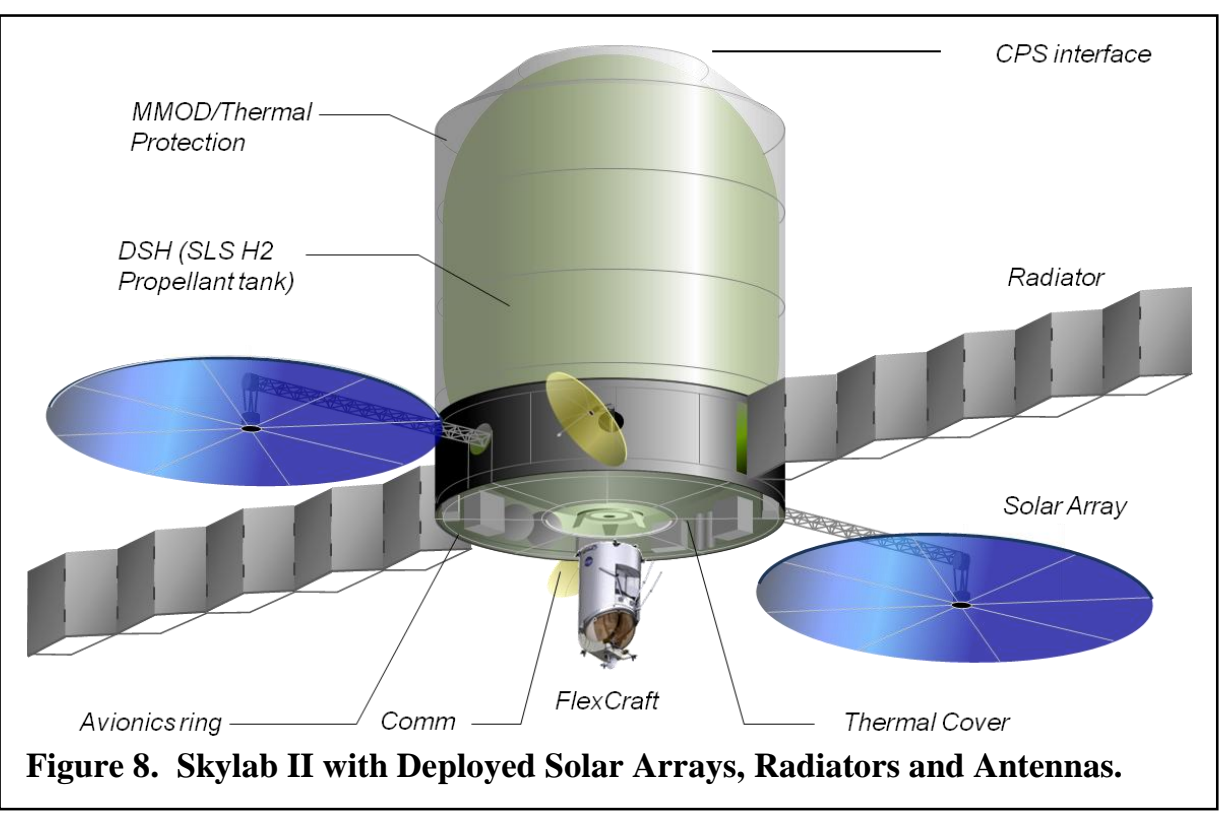

5 is to rendezvous with an awaiting MPCV/SEP at L1/L2 then return to Earth and the other is to take the MPCV as part of the mission assembly, then return to Earth directly without returning to L1/L2. The difference between the two is the mission specific energy required for a lagrangian rendezvous.

Longer missions not only translate into more consumables, but also into requirements for system technology and reliability, as well as the strategy for maintenance and repair. The Apollo Command

American Institute of Aeronautics and Astronautics 
Module provided Skylab astronauts with a lifeboat for emergency return. For asteroid and Mars missions, there are no emergency returns. This is an important but difficult to quantify distinction because it calls for greater vehicle autonomy and on-board capabilities that allow astronauts to resolve issues along the way. This requirement is not unique to the Skylab II configuration, but the additional volume allows designs that provide better accessibility and spares storage.

Figure 8 shows a conceptual design for Skylab II where the MPCV remains at the Earth-Moon Lagrangian point. One end connects to the Cryogenic Propulsion Stage (CPS) and the other uses a conventional avionics ring for mounting and deploying external hardware such as antennas, solar arrays and radiators. The thermal cover that protects ring-mounted hardware has an opening in the center that allows mating a single person spacecraft (FlexCraft) to the DSH. This same interface connects to an internal airlock in the event that suited extravehicular activity (EVA) is required (Figure 9). For deep space missions like asteroid exploration, EVA or FlexCraft operations are assumed to be short-term activities taking place only at the destination. Consequently, EVA from an airlock provides a reasonable solution for
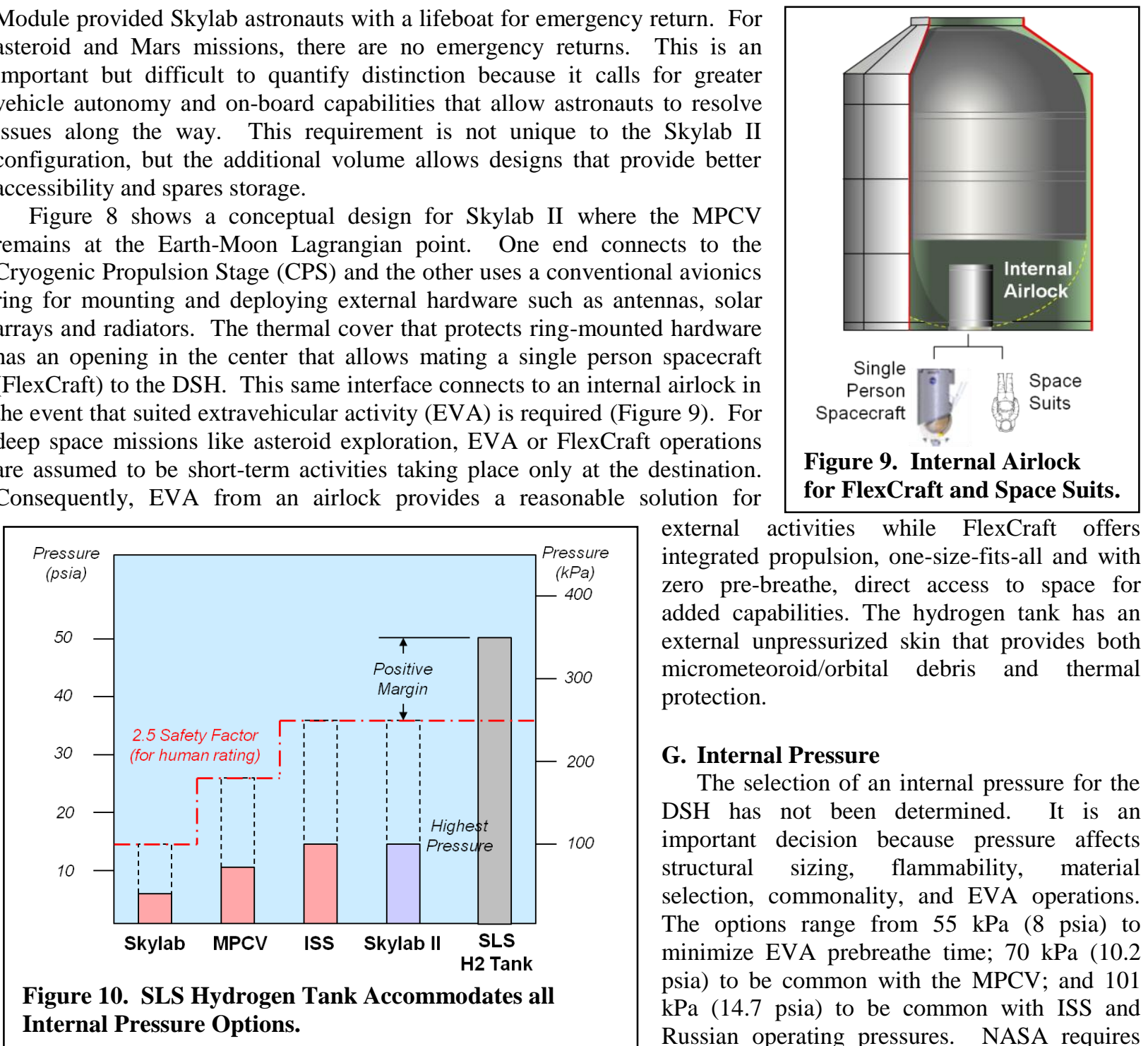

external activities while FlexCraft offers integrated propulsion, one-size-fits-all and with zero pre-breathe, direct access to space for added capabilities. The hydrogen tank has an external unpressurized skin that provides both micrometeoroid/orbital debris and thermal protection.

\section{G. Internal Pressure}

The selection of an internal pressure for the DSH has not been determined. It is an important decision because pressure affects structural sizing, flammability, material selection, commonality, and EVA operations. The options range from $55 \mathrm{kPa}(8 \mathrm{psia})$ to minimize EVA prebreathe time; $70 \mathrm{kPa}(10.2$ psia) to be common with the MPCV; and 101 $\mathrm{kPa}(14.7$ psia) to be common with ISS and Russian operating pressures. NASA requires that a human rated pressure vessel have a safety factor of 2.5. Ordinarily this would be an issue, but because the SLS hydrogen tank is designed for $345 \mathrm{kPa}$ (50 psia) not including the 1.4 safety factor, all pressure options are acceptable (Figure 10). This was similar with the original Skylab. A 5 psia internal pressure was selected because it was common with the Apollo systems however; the Saturn $\mathrm{V}$ hydrogen tank was designed for $345 \mathrm{kPa}(50 \mathrm{psia})$.

\section{H. SLS System Benefits}

Because the hydrogen tank is part of the launch vehicle, the interfaces are well understood. Dimensions, load path, handling hard points and fixtures are all common with the launch vehicle. Furthermore, it is possible to share production facilities and transportation equipment. Mating Skylab II with the launch vehicle uses the same facilities and stacking hardware as the hydrogen tank. Another benefit is that, with a common shroud, Skylab II can fly on not only the lowest lift configuration $(70 \mathrm{mt})$, but on all others. See Figure 11.

Low launch vehicle tare mass is particularly important to

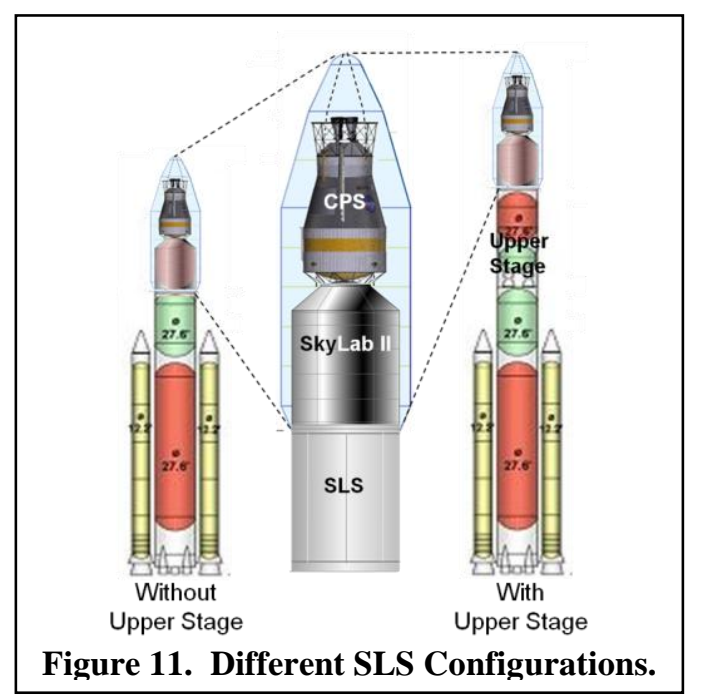




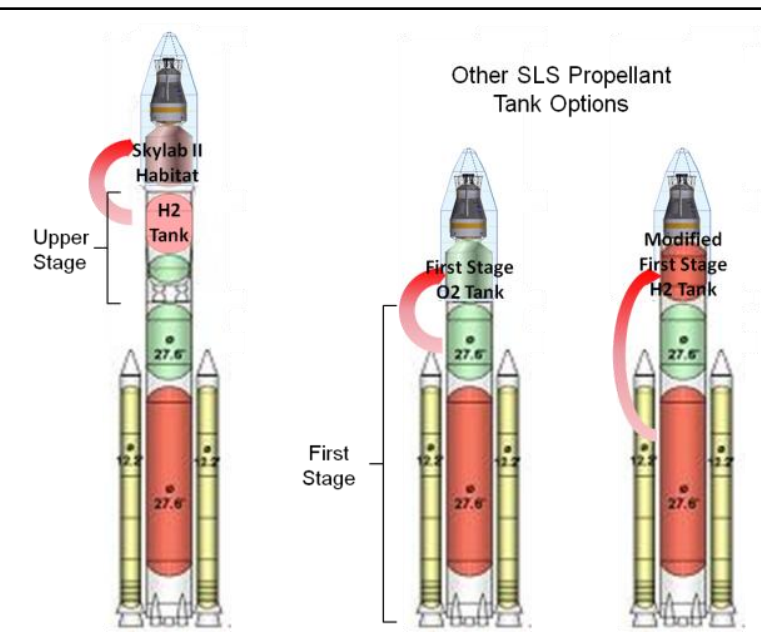

Figure 12. First stage SLS tanks for the DSH

launch vehicles and this translates into a significant benefit for the DSH mass. The current SLS upper stage $\mathrm{H} 2$ tank weighs $4200 \mathrm{~kg}(9240 \mathrm{lbm})$. This is an exceptionally light weight pressure vessel; equivalent to two sport utility vehicles.

The simplest approach is to use a tank off the production line then outfit it as a DSH. Figure 12 shows other options include using the first stage oxygen tank or the end domes of the first stage hydrogen tank welded to a shortened barrel section. Either approach offer the same diameter with the oxygen tank providing a $9.5 \mathrm{~m}$ (373 in.) barrel section and thus greater volume than the upper stage hydrogen tank. Both options are particularly attractive if the DSH requires early acquisition of the pressure vessel.

\section{Attractive Cost}

The Skylab II pressure vessel could be "free." Before a propellant tank is used for launch, a structural test article (STA) is constructed to verify it meets the engineering specifications. Like other NASA programs, the STAs are retained as long as they serve a purpose and in this case, it would be a DSH. This means there is no cost for the single largest element of the DSH. If for some reason the STA is not available, the project still avoids the DDT\&E of the pressure vessel by acquiring another tank off the assembly line.

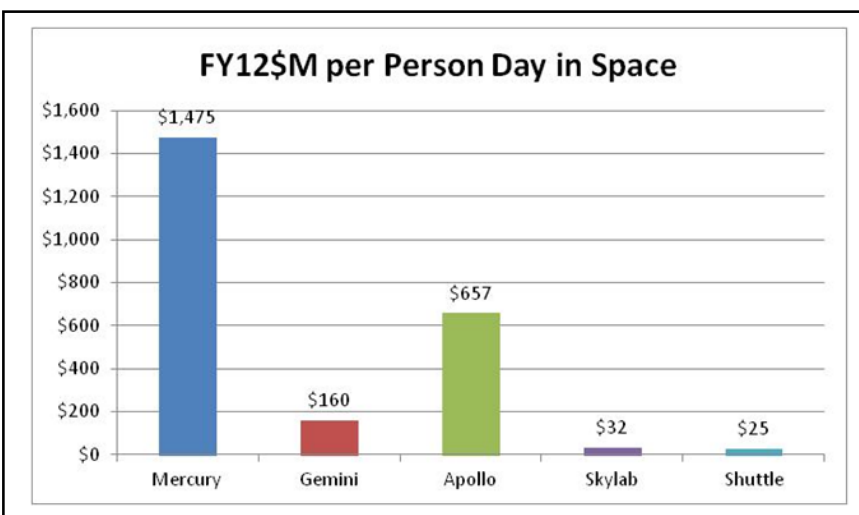

Figure 13a.

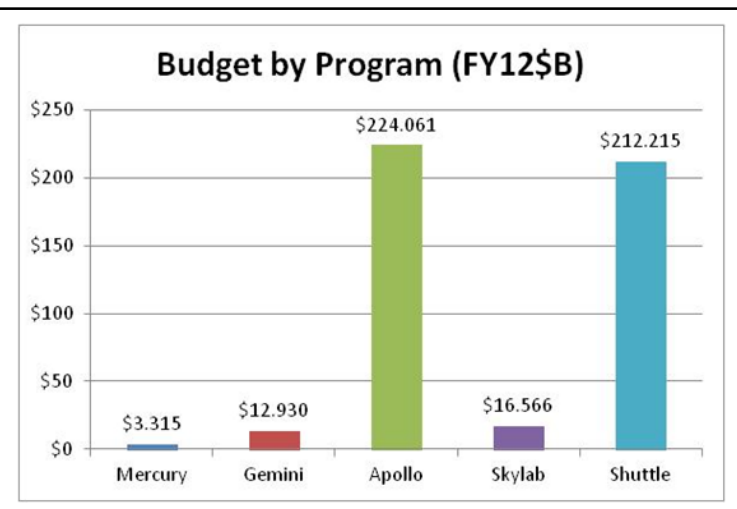

Figure 13b.

Low Skylab costs result from heritage hardware and continuous on-orbit operations. (NASA)

There are additional cost benefits. With the use of heritage hardware, Skylab II would show the same economies as the original Skylab. This is demonstrated by a recent Human Space Flight Value Study that compared major NASA programs. The analysis itself relied on publically available budget data, normalized to constant Fiscal Year

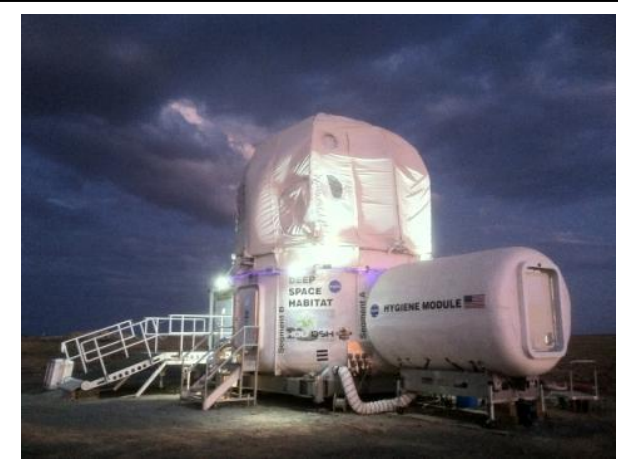

Figure 14. HDU-DSH, $5 \mathrm{~m}$ diameter during NASA field analog tests.
2012 dollars. As shown in Figure 13a, next to the Shuttle, Skylab was the lowest cost per person day in space. This is attributable to using Apollo heritage hardware and having three crews with long missions. And, in Figure 13b, it is easy to see the benefit to budgeted cost by using heritage hardware.

\section{Current Work}

NASA's Advanced Exploration Systems (AES) DSH project designed and built a $5 \mathrm{~m}$ diameter vertical cylindrical prototype habitat called the Habitat Demonstration Unit (HDU). The HDUDSH consisted of a hard shell module portion, outfitted as a laboratory with low to medium fidelity functional workstations, and an upper inflatable membrane dome loft for habitation (Figure 14). In parallel, an ISS-derived developmental prototype is being

American Institute of Aeronautics and Astronautics 
constructed based on ISS heritage module dimensions and configuration. The workstations and layout of these two test articles were dictated by multiple studies on DSH Design Reference Missions (DRM). The next stage of research will outfit Johnson Space Center's 20ft (6m dia.) vacuum chamber as a habitat test bed, where all the lessons of internal configuration from HDU-DSH and ISS-derived habitats will be applied (Figure 15). Though the diameter of the $20 \mathrm{ft}$ chamber differs from the diameter of the SLS hydrogen tank, enough similarities remain to allow for physical tests and demonstrations that would provide some answers to the practicality of building a Skylab II DSH, in addition to other potential non-SLS-derived DSH configurations

\section{Conclusion}

The Skylab II approach meets essential engineering and habitable volume requirements and in light of projected budget constraints, offers a low cost option for flying a Deep Space Habitat. There is no need for multiple launches and on-orbit assembly, because the entire DSH can be delivered fully outfitted in a single launch. Furthermore, SLS will be the work horse for human exploration beyond LEO and the Skylab II DSH would share common facilities, support and transportation equipment.

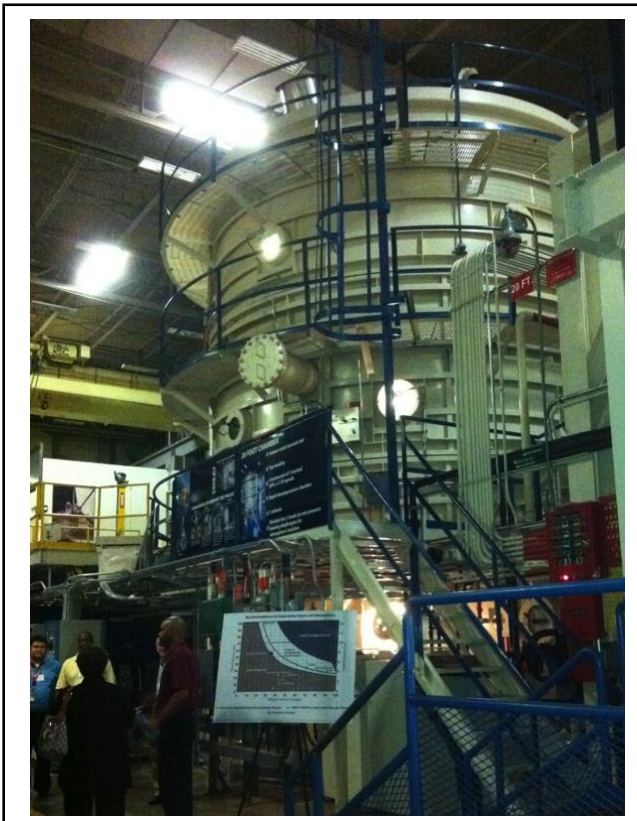

Figure 15. Twenty foot Chamber for Skylab II and similar volumes.

Current demonstrations and testing in vertical cylinder configuration developmental prototype habitats will provide experimental data toward a Skylab II configuration habitat.

\section{References}

"Deep Space Habitat Configurations based on International Space Station Systems," Smitherman, D., et al, Global Space Exploration Conference, Washington, D.C., May, 2012, GLEX 2012.01.1.8x12219

Dunbar, A. J., Waring, S. P., Power to Explore, A History of Marshall Space Flight Center 1060-1990, National Aeronautics and Space Administration History Office, NASA SP 4313, 1999.

International Space Station, NASA Fact and Figures, Page Editor: Amiko Kauderer, NASA Official: Brian Dunbar, Page Last Updated: September 20, 2011.

Prince, A., Carson. W., Human Spaceflight Value Study, MSFC Engineering Cost Office, May 2012. 


\section{Skylab II}

Making a Deep Space Habitat from a Space Launch System Propellant Tank

\section{September 12, 2012}

SKYLAB

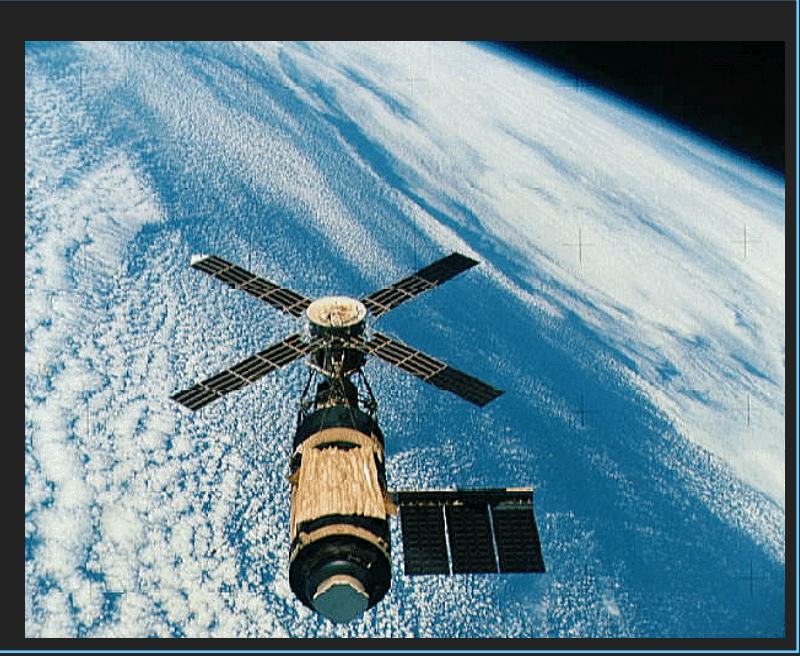

SKYLAB II

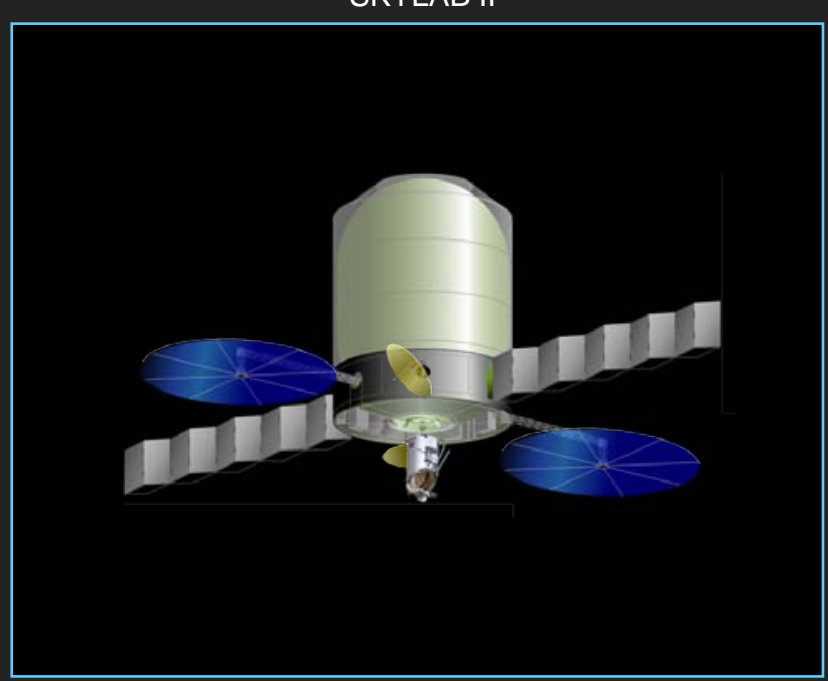




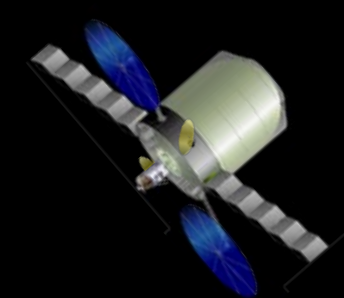



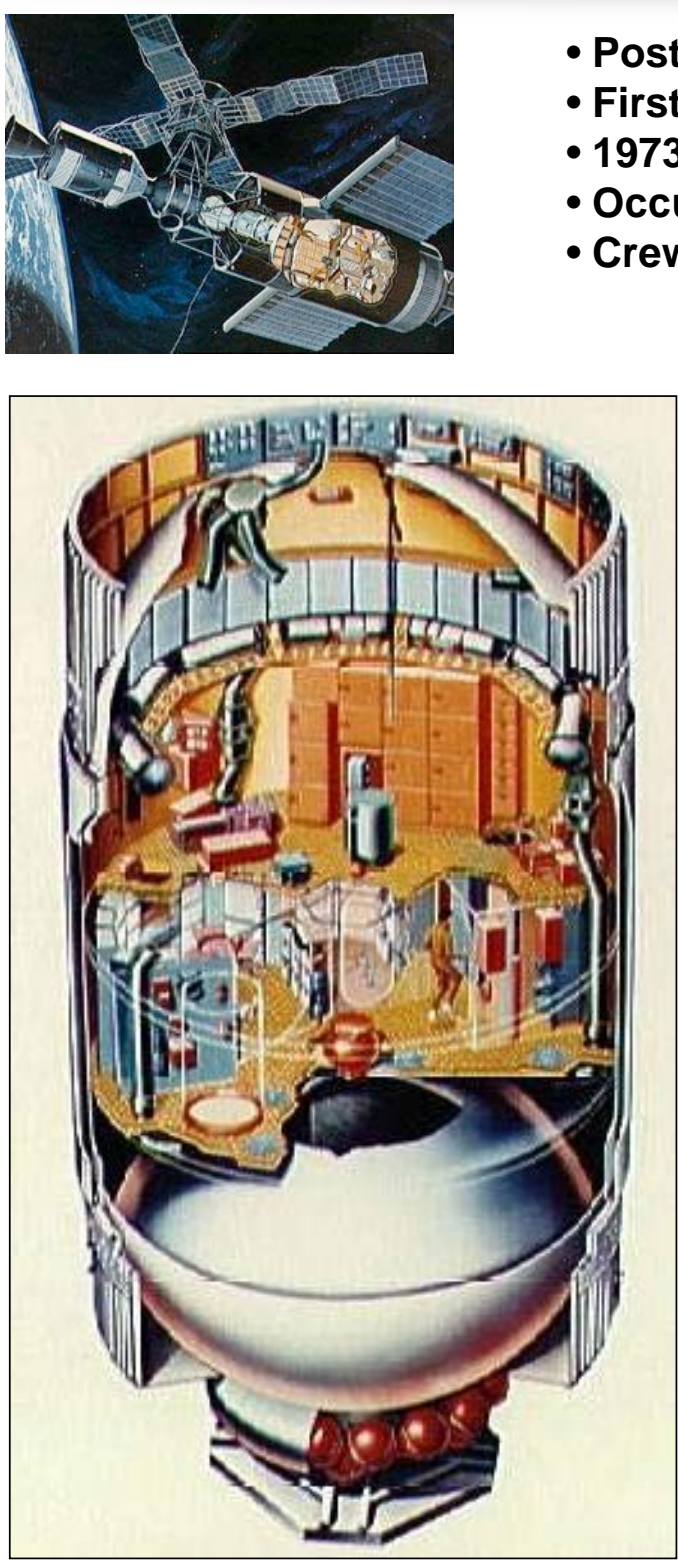

National Aeronautics and Space Administration
- Post Apollo (used Apollo assets)

- First US Space Station

- 1973 Saturn V launch (fully provisioned)

- Occupied by 3 crews, 3 astronauts each

- Crew duration: 28, 59 and 84 days
- Launch mass 77,088 kg (169,950 lb)

- "Dry" Workshop ( $3^{\text {rd }}$ stage propellant tank)

- Included telescope, airlock and docking adaptor

- LEO $440 \mathrm{~km}$ altitude, $50^{\circ}$ inclination

- Last crew 1974, re-entered 1979

\section{APOLLO TELESCOPE MOUNT}
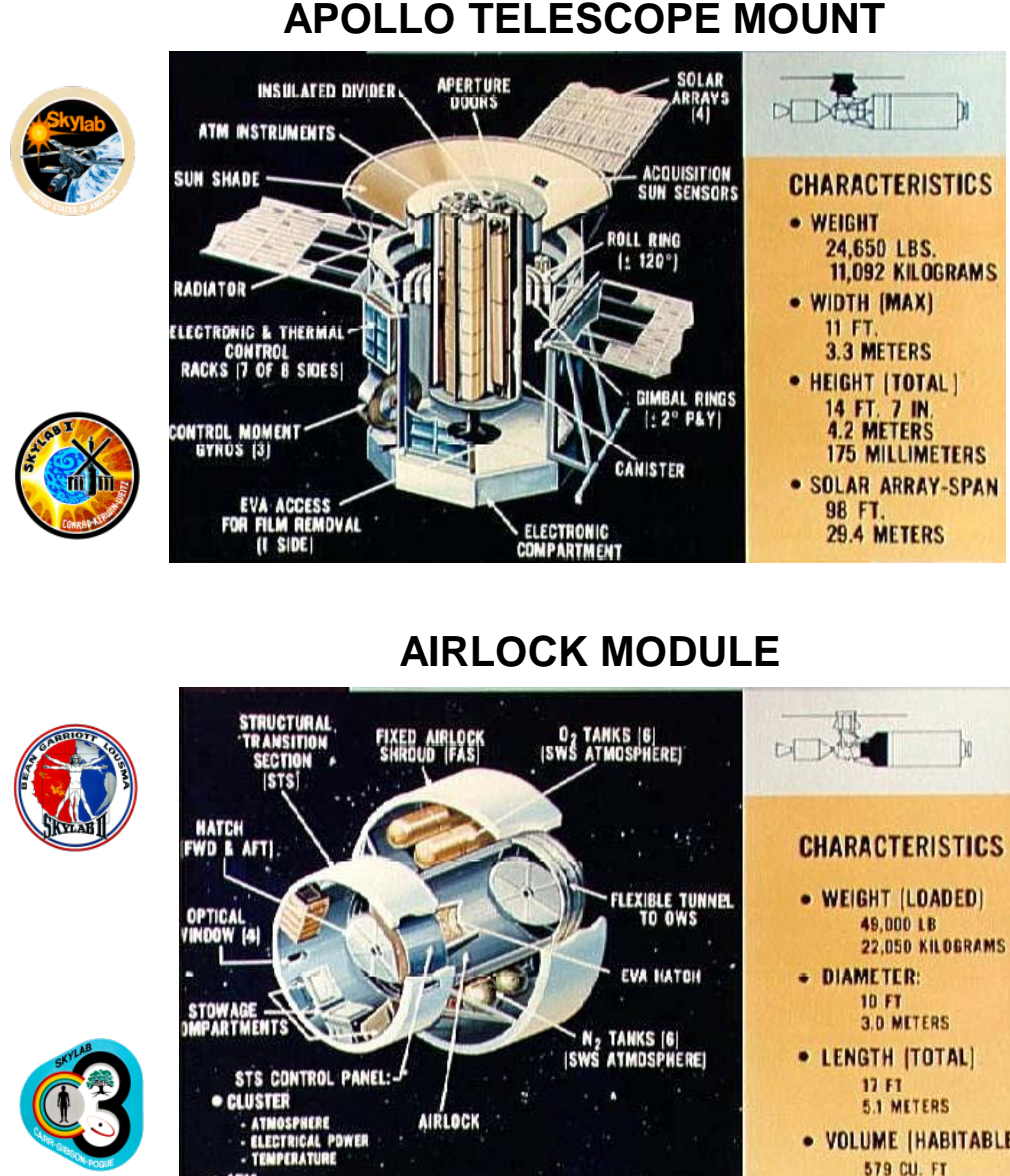

\section{AIRLOCK MODULE}

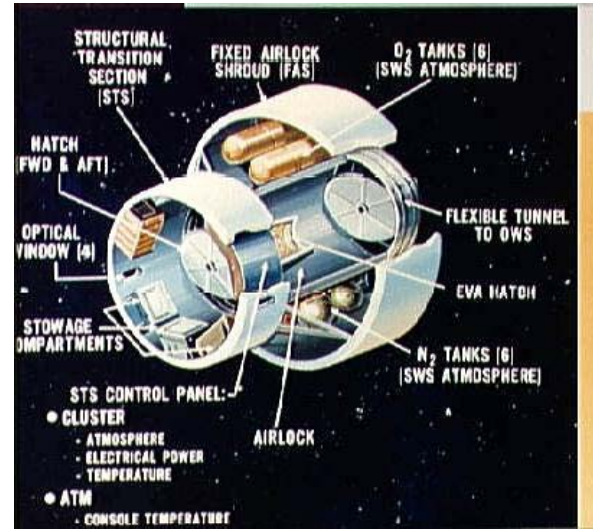

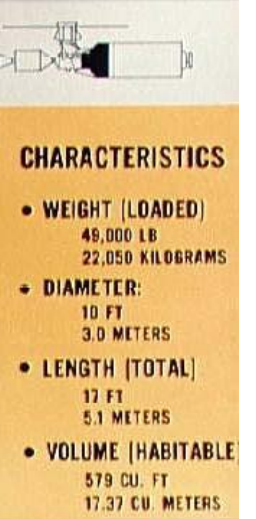

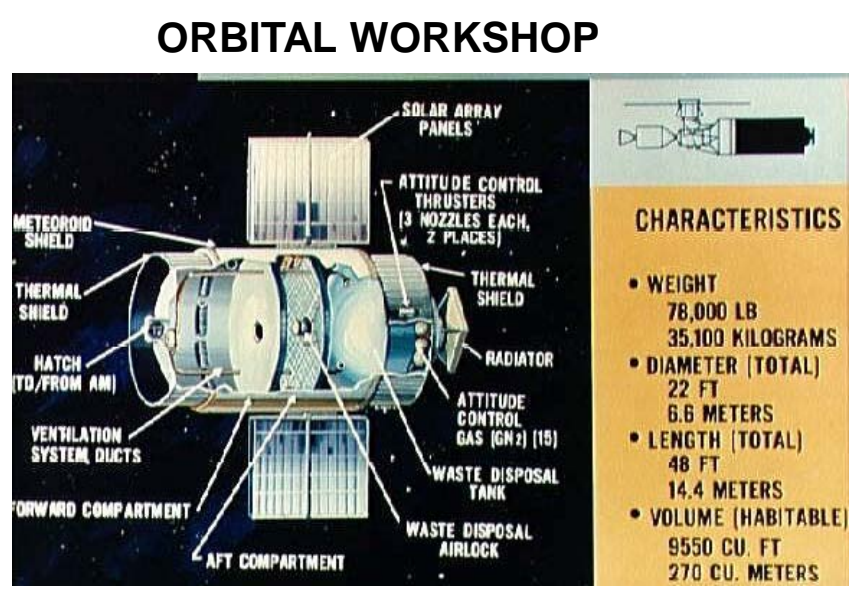

\section{MULTIPLE DOCKING ADAPTOR}

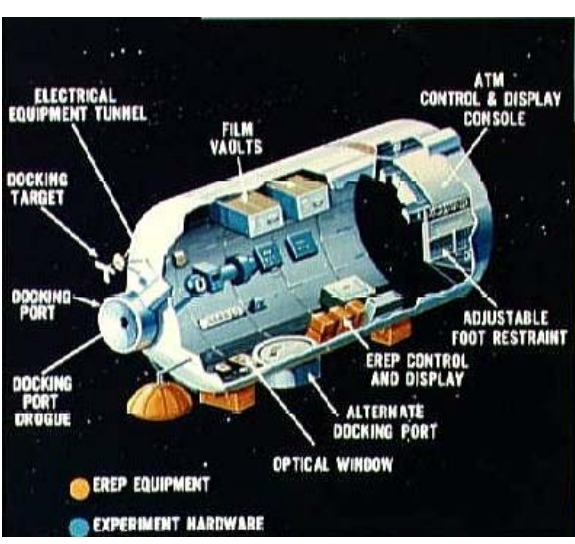

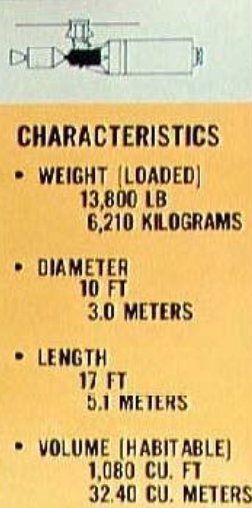


NAşA Heavy Lift, Large Diameter, Single Launch

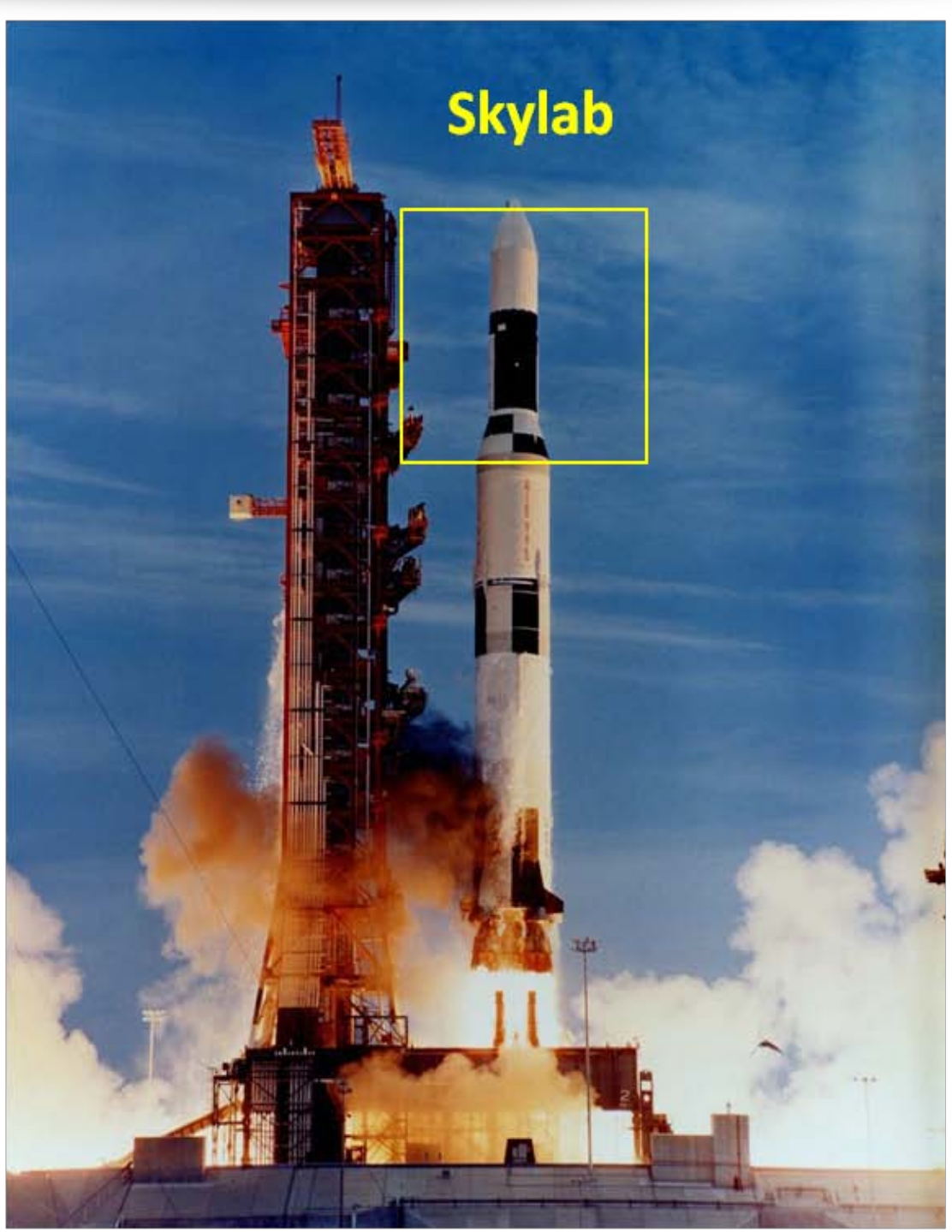

Saturn V
Skylab II

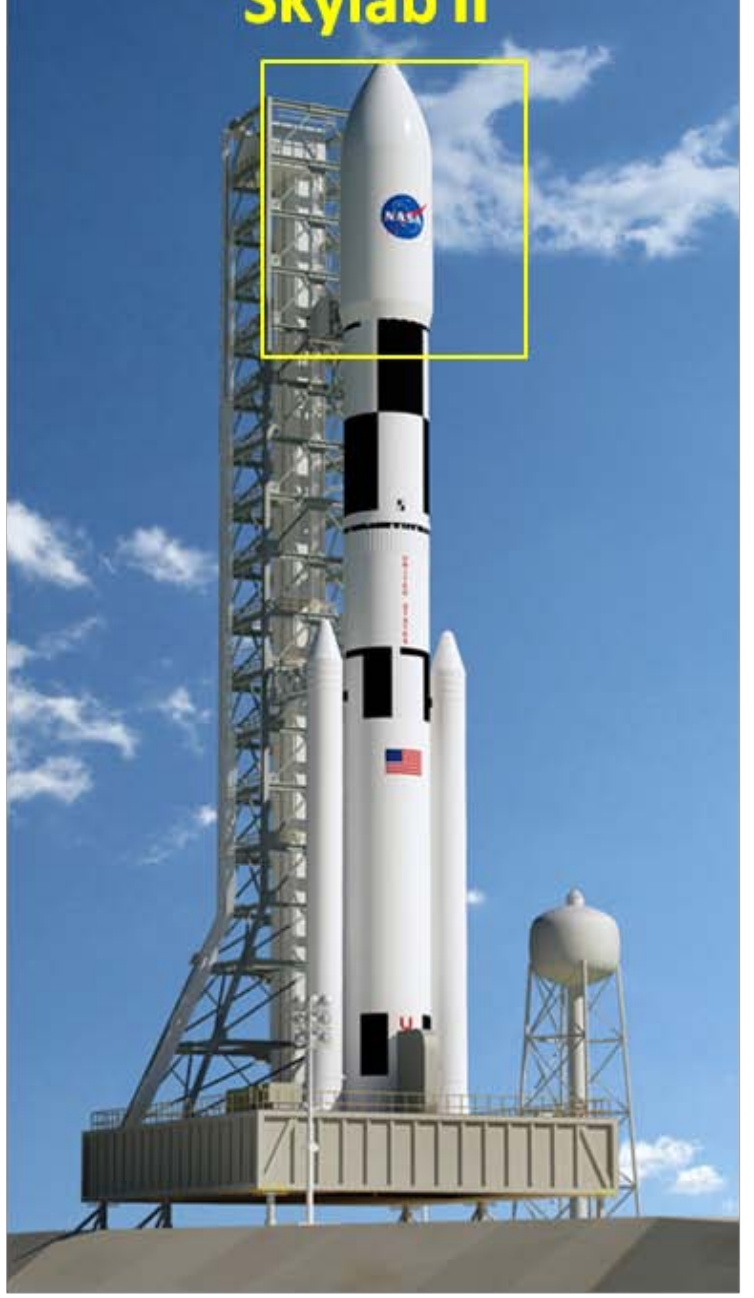

Space Launch System 


\section{NAsA Operational Assemblies}

Skylab

Solar Astronomy

Earth Resources Experiment Package

Long-term Habitation

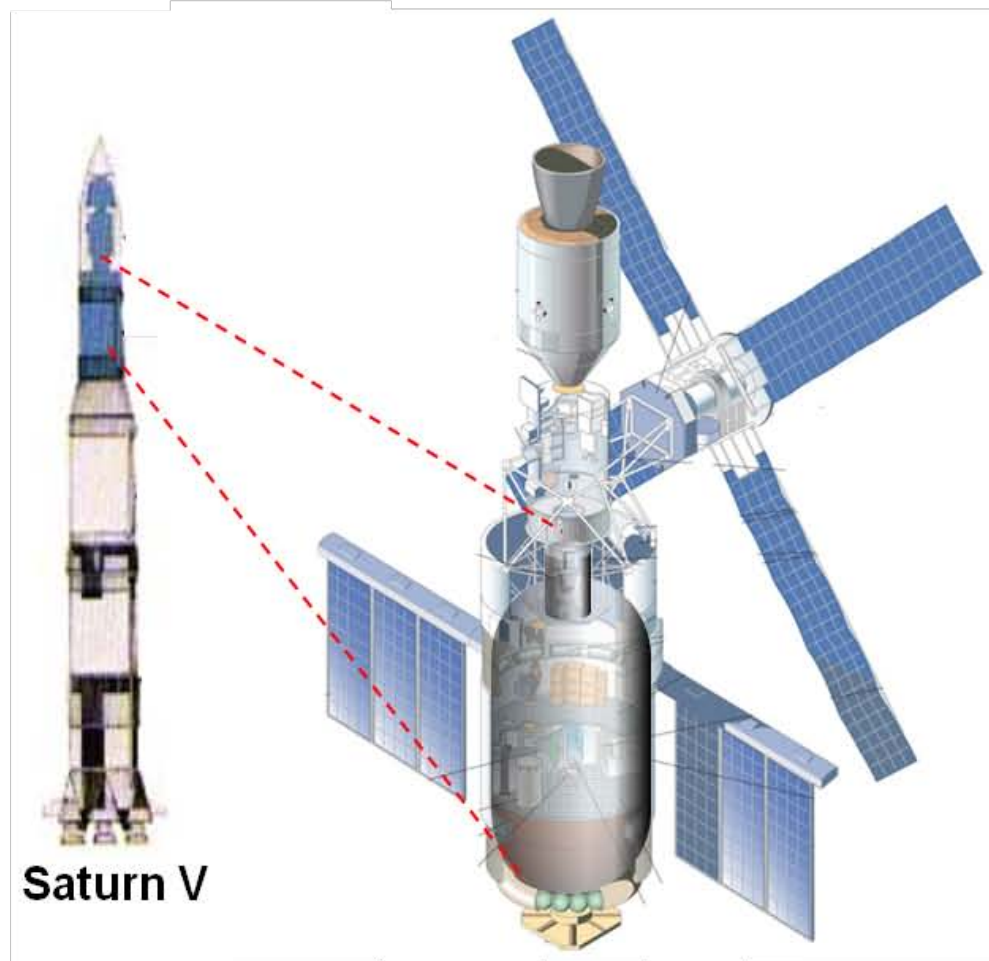

Low Earth Orbit

Three crews with 3 astronauts each

Longest Mission: 84 days
Skylab II

Earth-Moon Way Station

Mars/Asteroid Exploration

Very Long Habitation

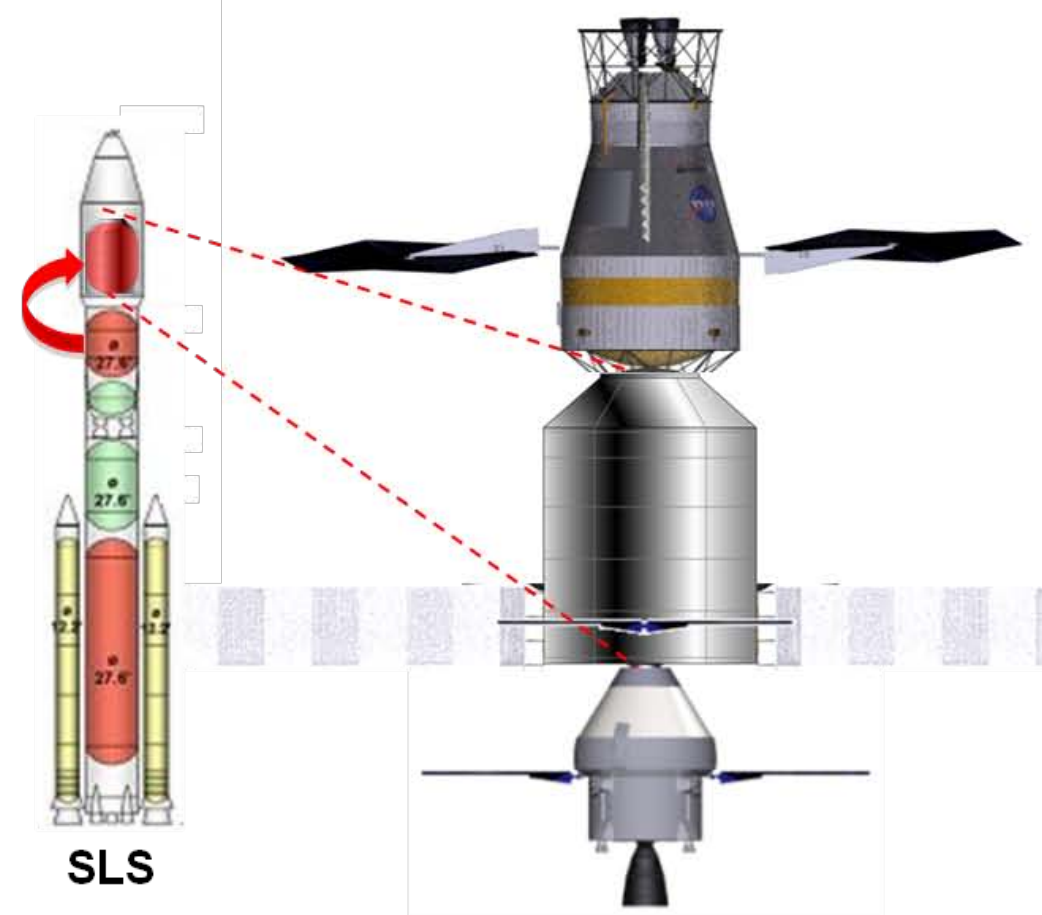

Beyond Low Earth Orbit

Multiple crews with 4 astronauts each

Longest Mission 500 days 


\section{NA SA \\ SLS Upper Stage H2 Tank}

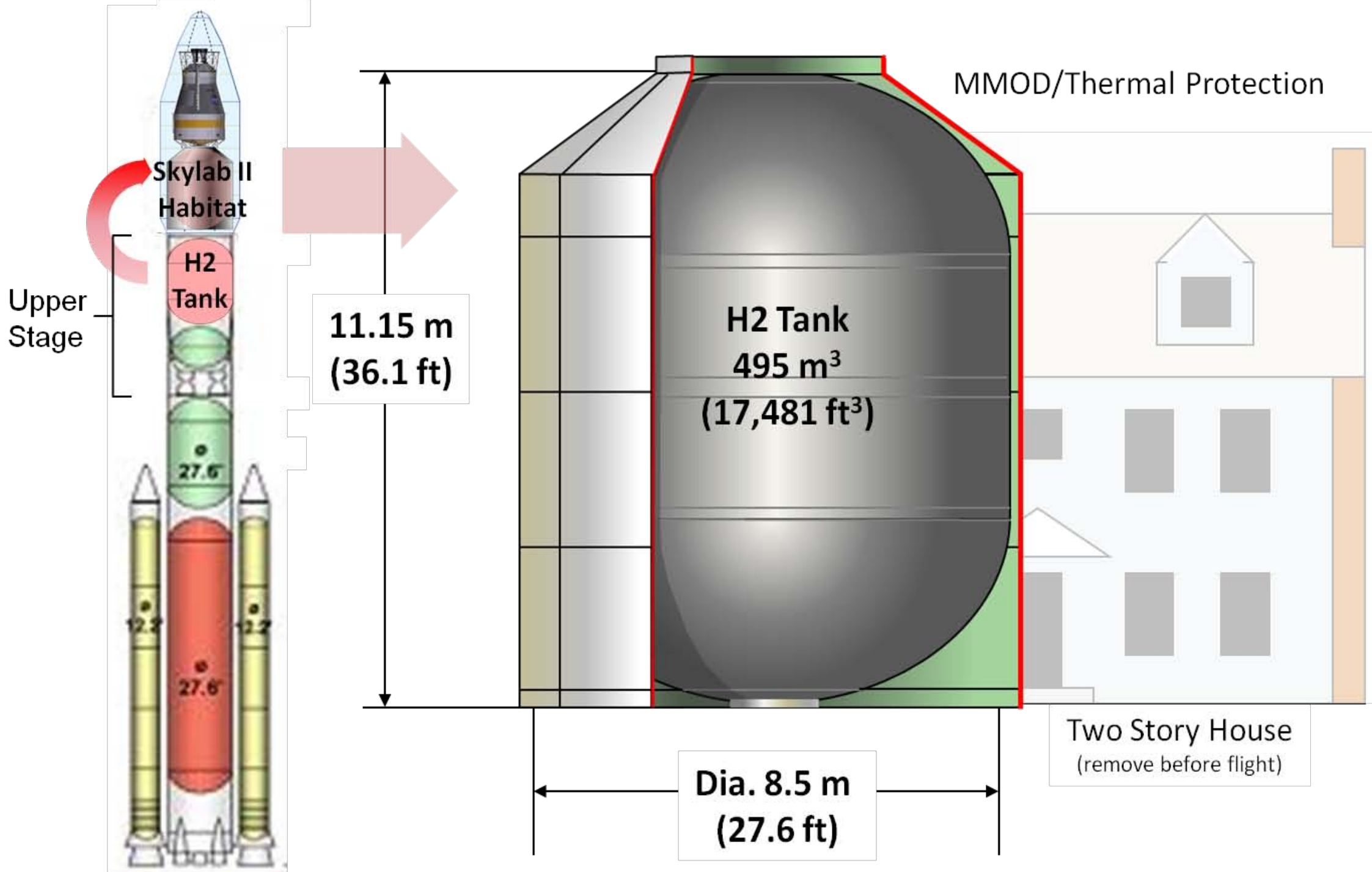




\section{NAsa Common with Shuttle External Tank}

SLS based on External Tank

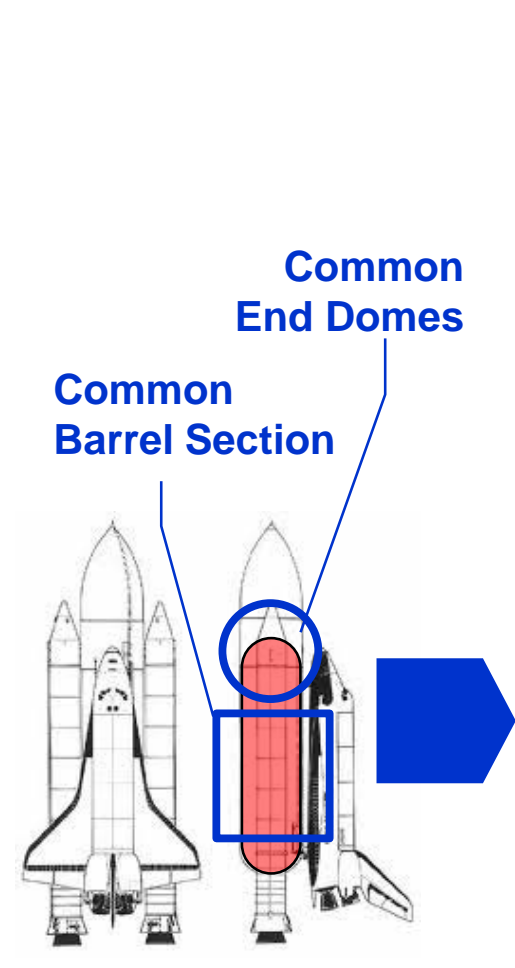

External Tank

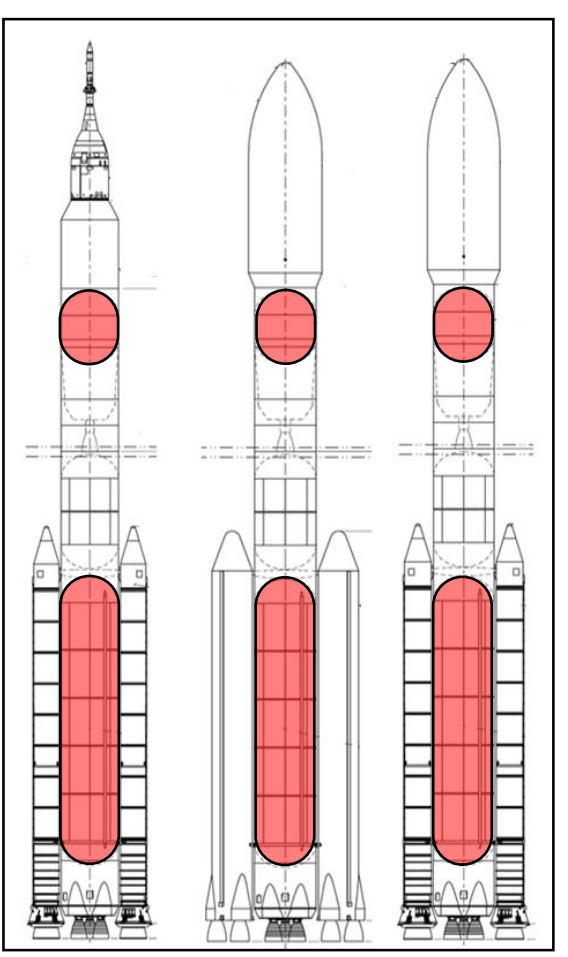

SLS Family
Person shows scale of the $\mathrm{H} 2$ Tank

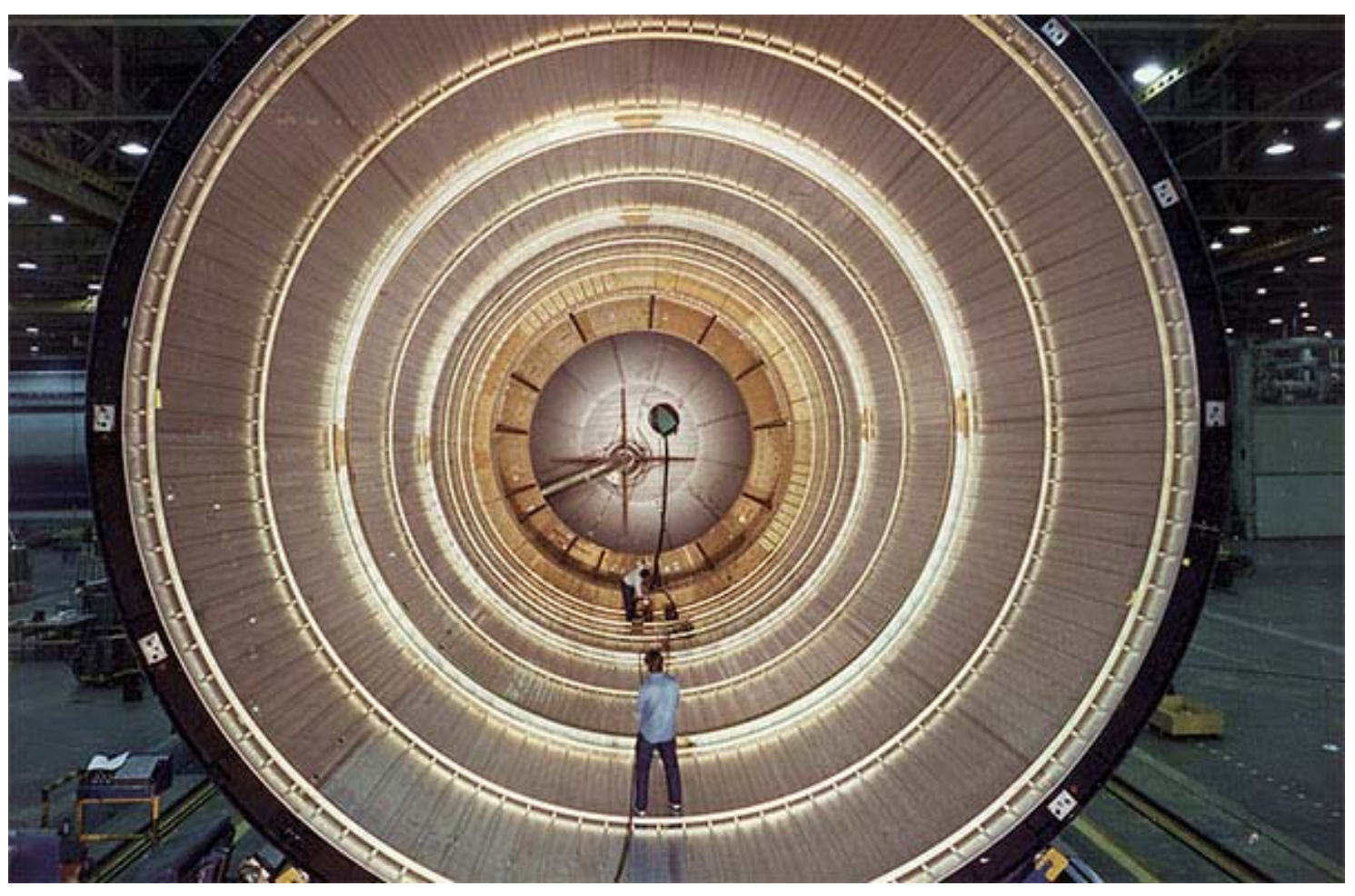

DSH would use the same SLS Facility and Personnel

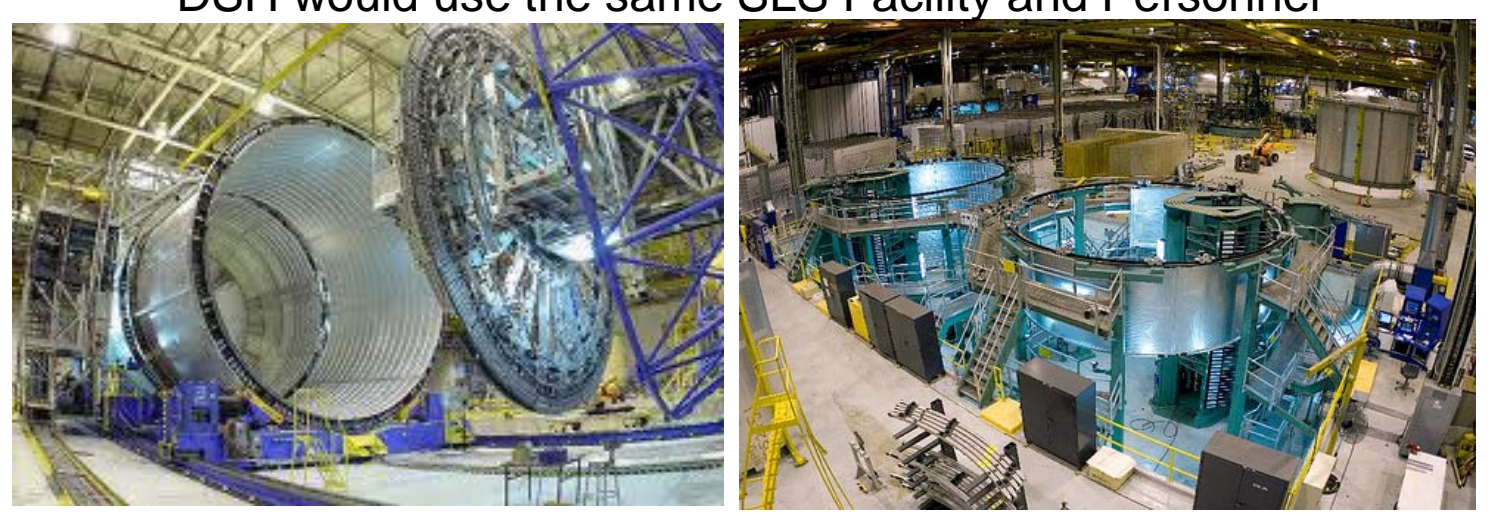




\section{NAsA Ample Volume for Long Missions}

\section{Crew Volume per Duration}

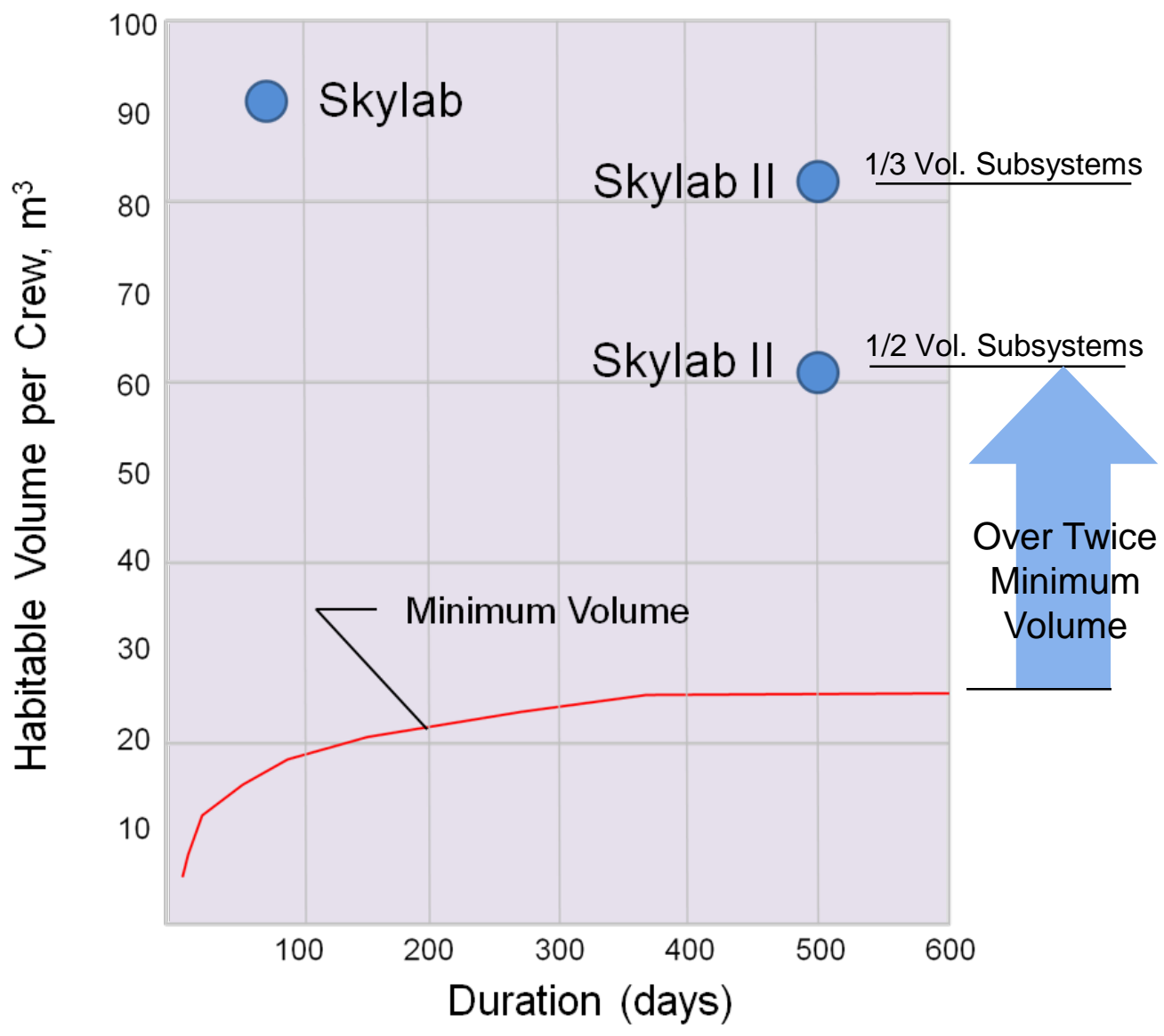

Additional DSH volume allows:

- Subsystems designed for servicing

- Improved access to utilities

- Improved access to stowage
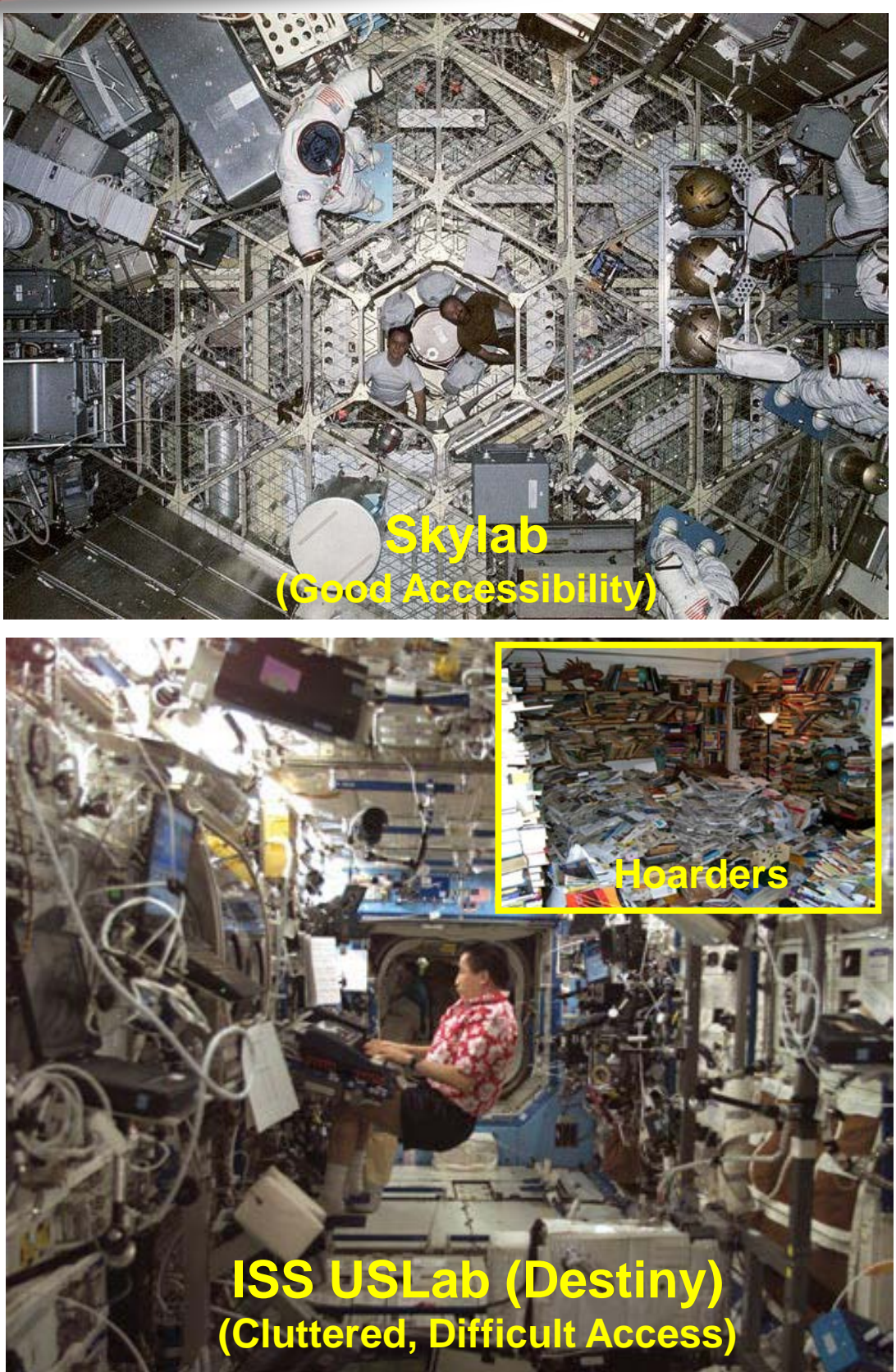


\section{NASA Habitat Configuration}

Deep Space Habitat

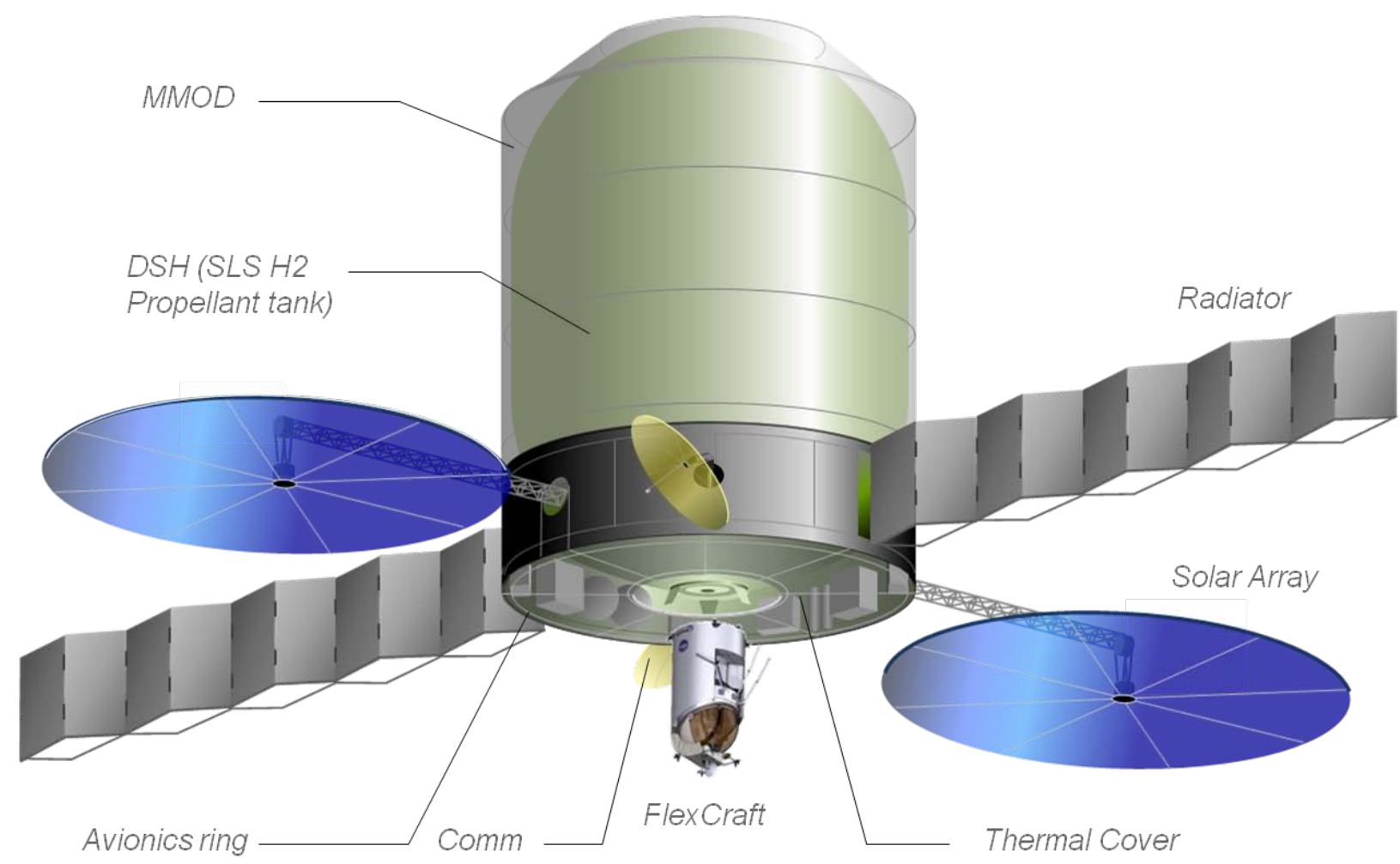

Deep Space Habitat As Earth-Moon L2 Way Point
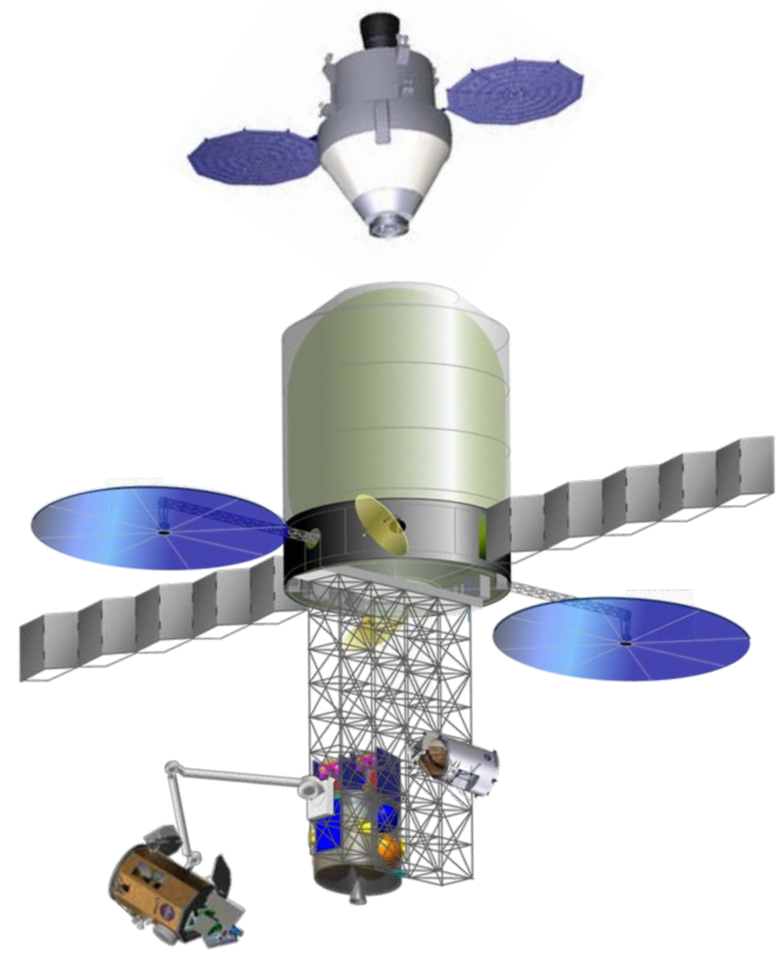


\section{NAgA Exceeds Human Safety Factor for all Pressures}

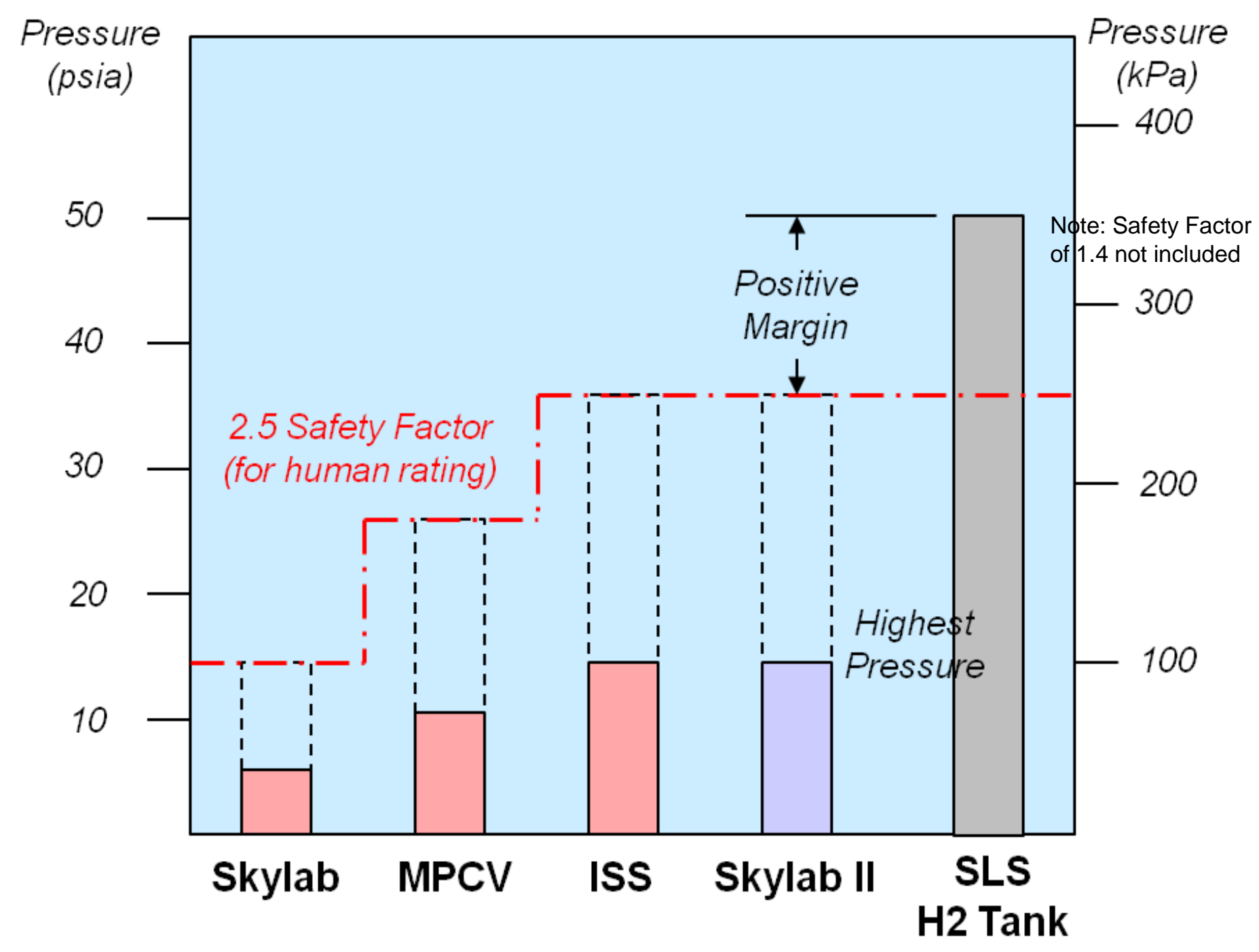




\section{NA \\ Deep Space Radiation}

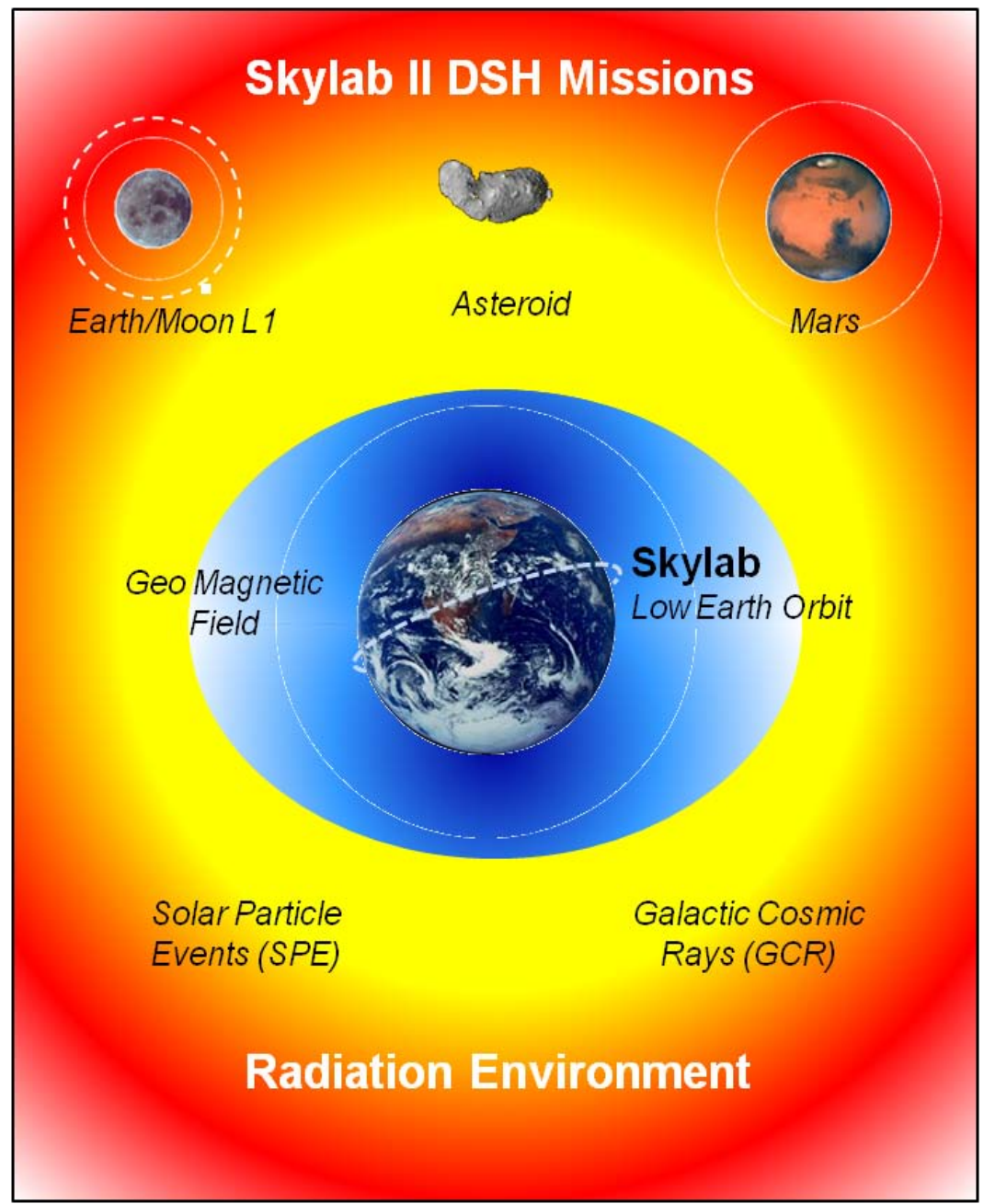

“Ugly” heavy solution for GCR and SPE

(or, how I learned to love bunkers)

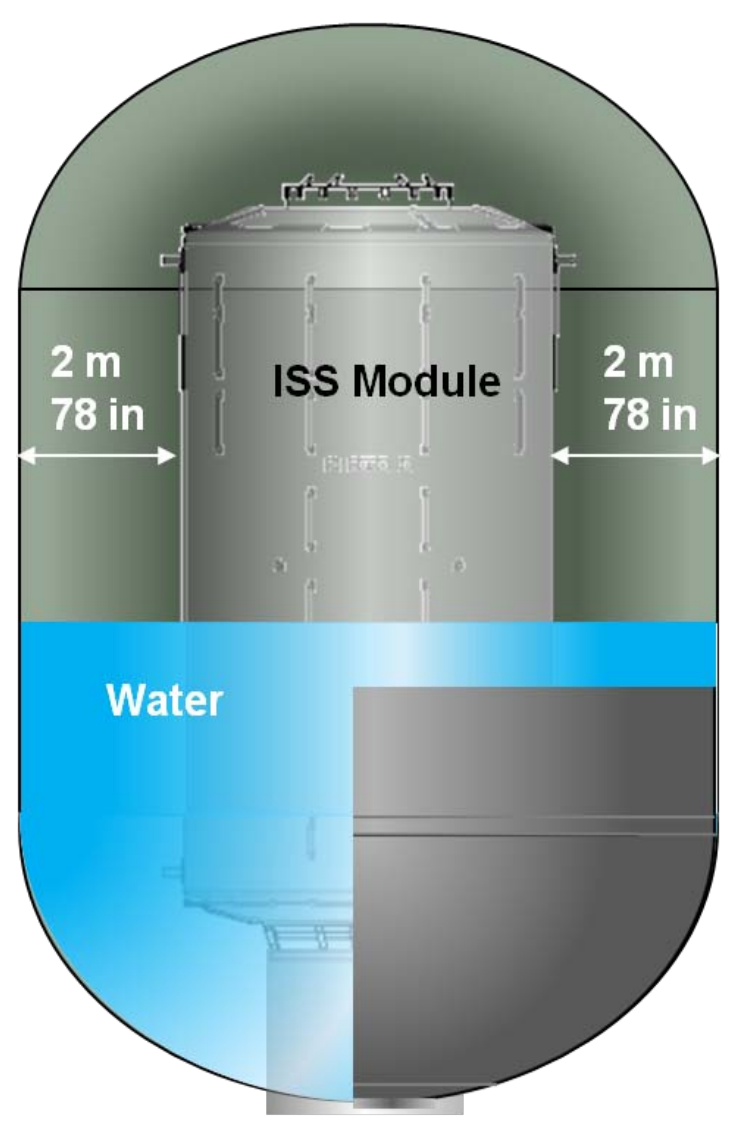




\section{NASA Comparisons}

\section{LH2 Tank Weighs less than 2 SUVs}

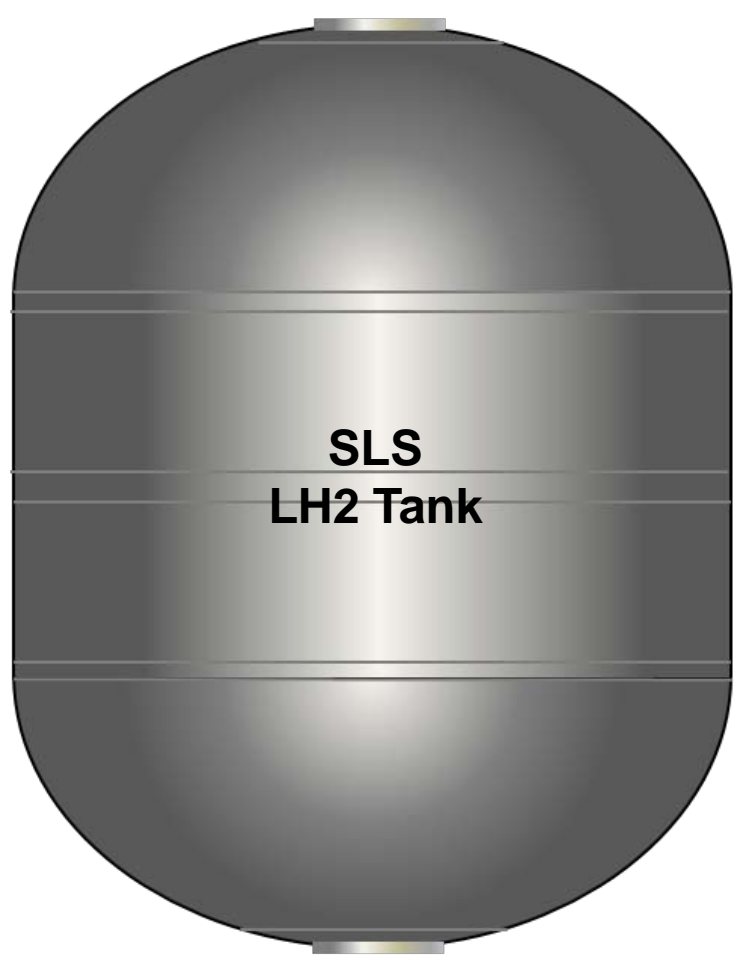

$4200 \mathrm{~kg}$

$(9,240 \mathrm{lb})$
Sport Utility Vehicle $2631 \mathrm{~kg}(5800 \mathrm{lb})$
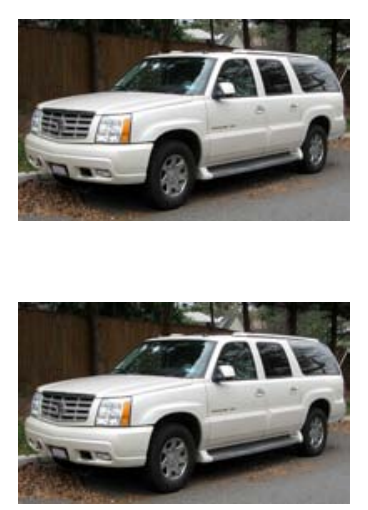

$5262 \mathbf{~ k g}$ $(11,600 \mathrm{lb})$

\section{Outfitting Weighs less than LH2 Propellant}

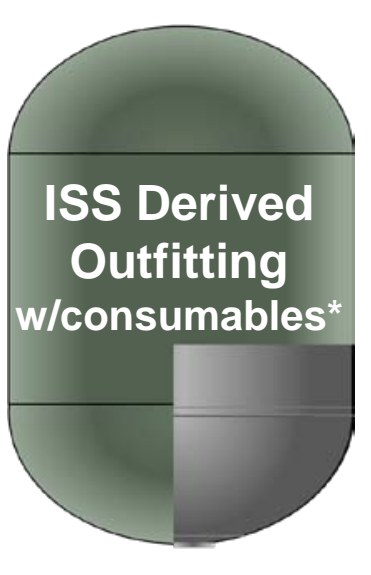

$31,000 \mathrm{~kg}$ $(68,343 \mathrm{lb})$

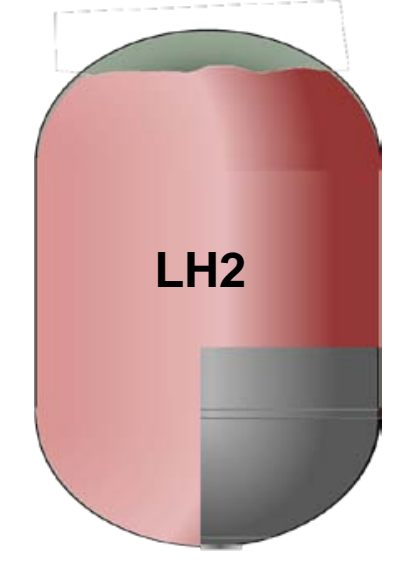

$33,100 \mathrm{~kg}$ $(72,960 \mathrm{lb})$
-500 Day configuration from Deep Space Habitat Configurations Based on ISS Systems, Advanced Exploration Systems, NASA, MSFC, December 2011 


\section{NAsA External Equipment and Airlock}
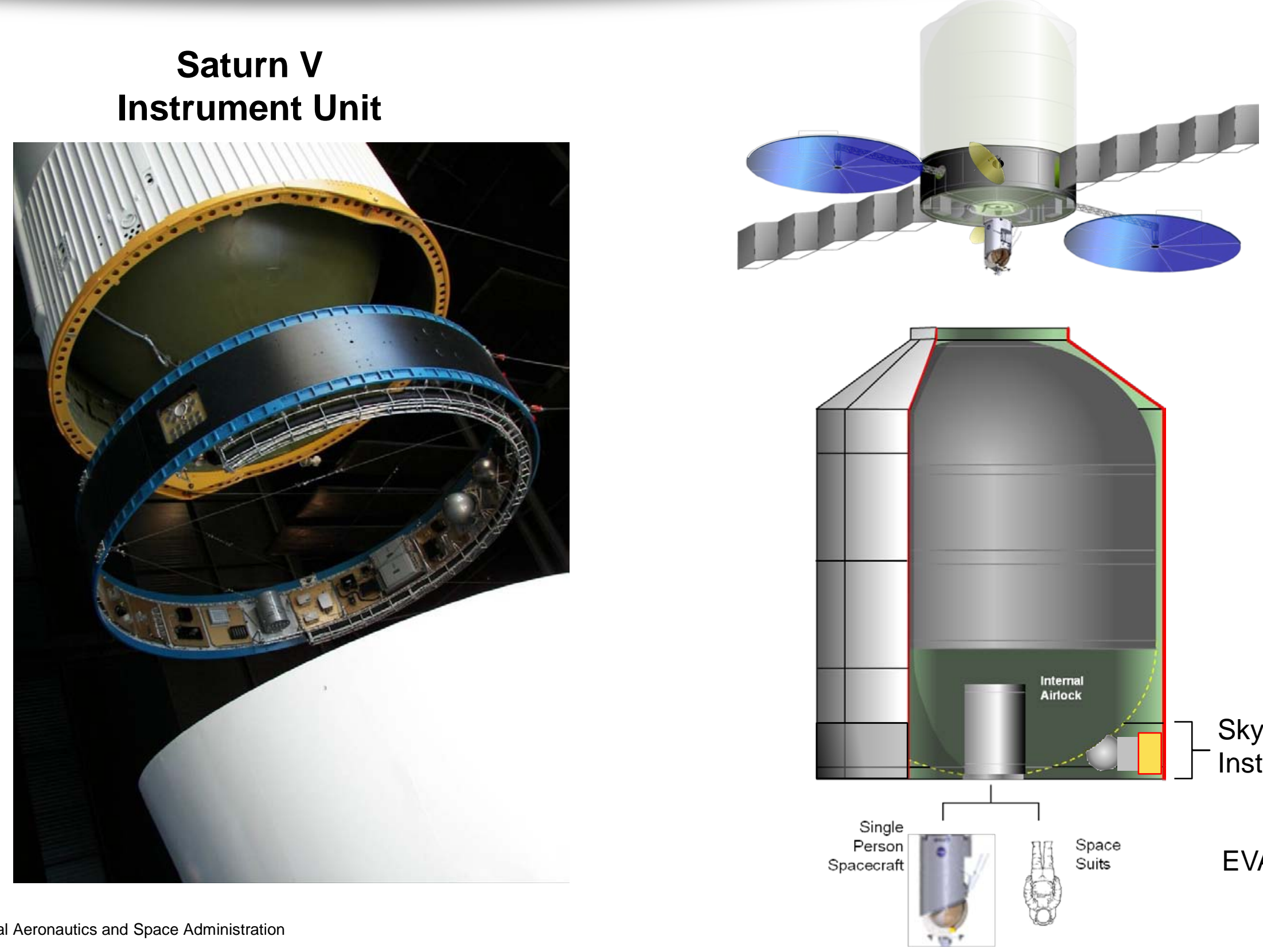

Skylab II

Instrument Unit

EVA Options 


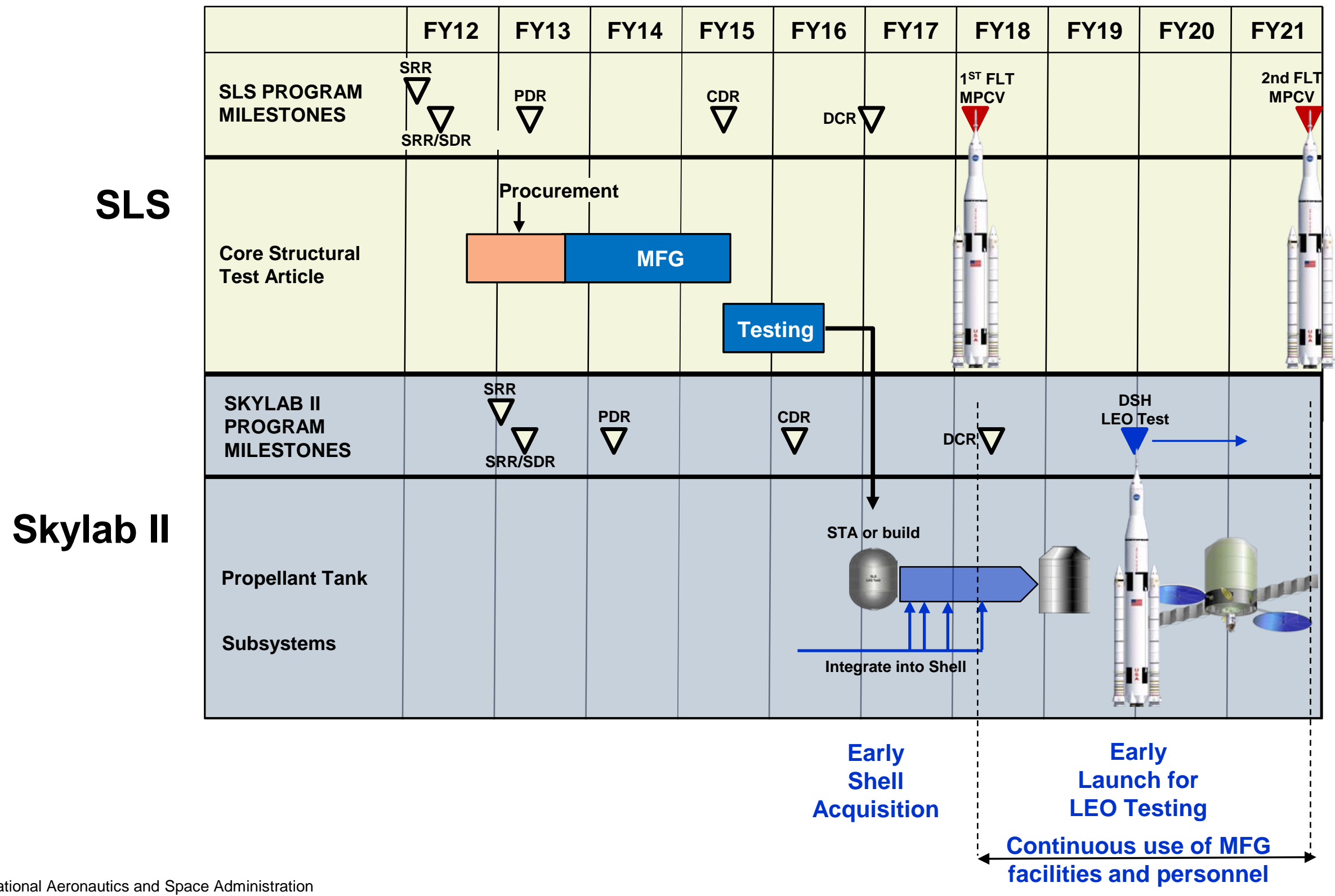




\section{NAsA Reusability and Heritage Hardware Reduce Cost}

\section{Human Spaceflight Value Study*}

All budget data is normalized to FY12\$ using the NASA new start inflation index titled "NASA FY11 Inflation Tables to be Used in FY12"
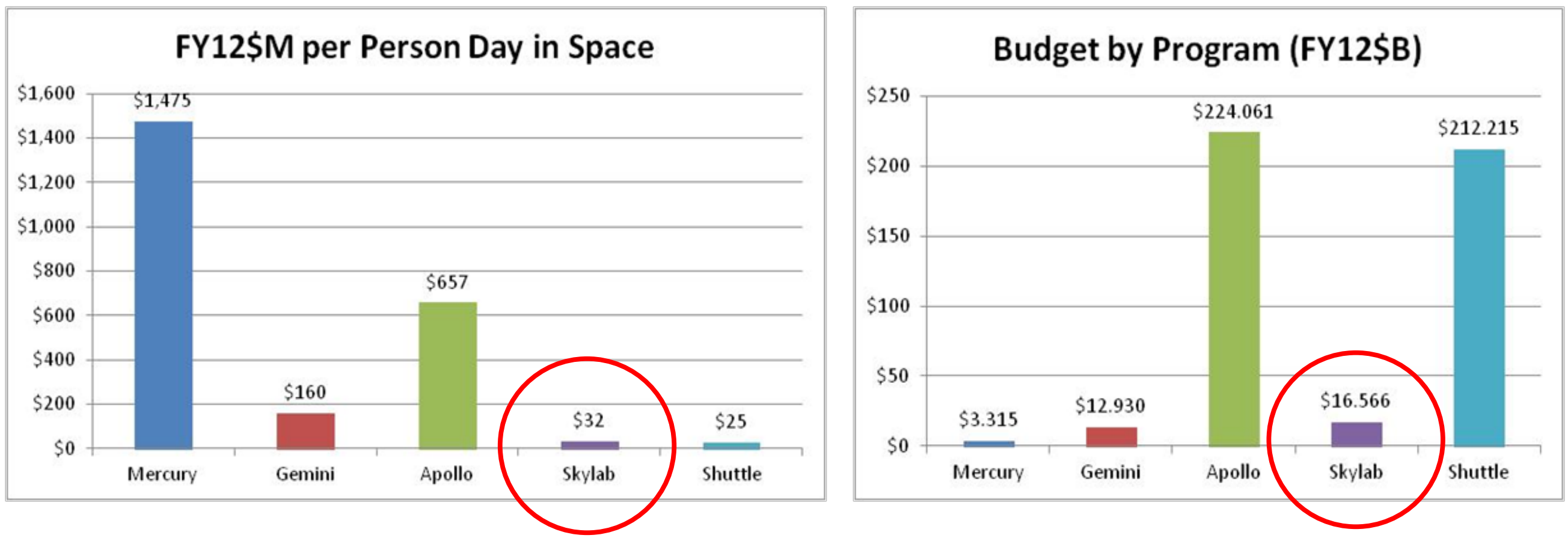


\section{NASA Current Work}

NASA's Advanced Exploration Systems Habitation Demonstration Unit

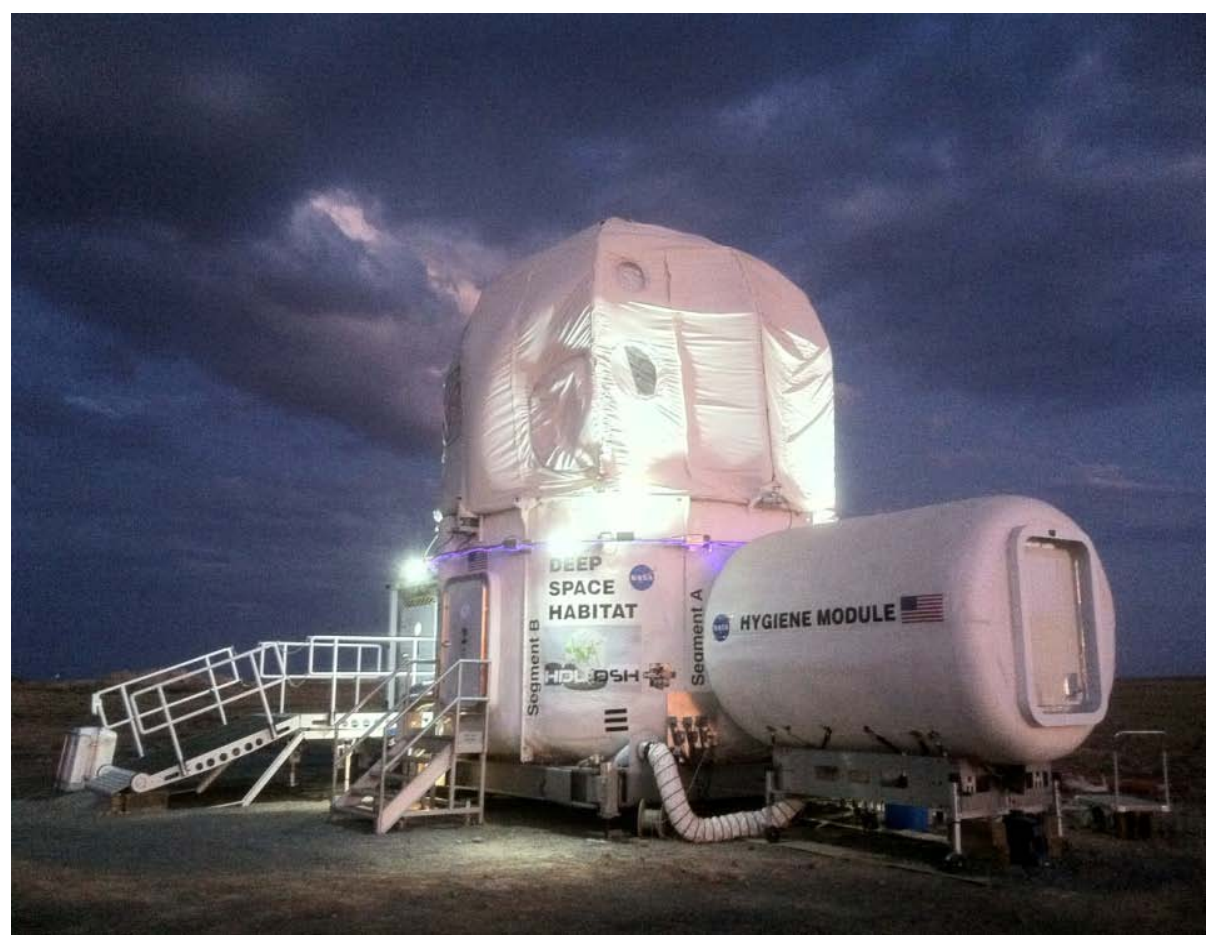

NASA's Johnson Space Center $6 \mathrm{~m}(20 \mathrm{ft}) \mathrm{DSH}$ Test bed

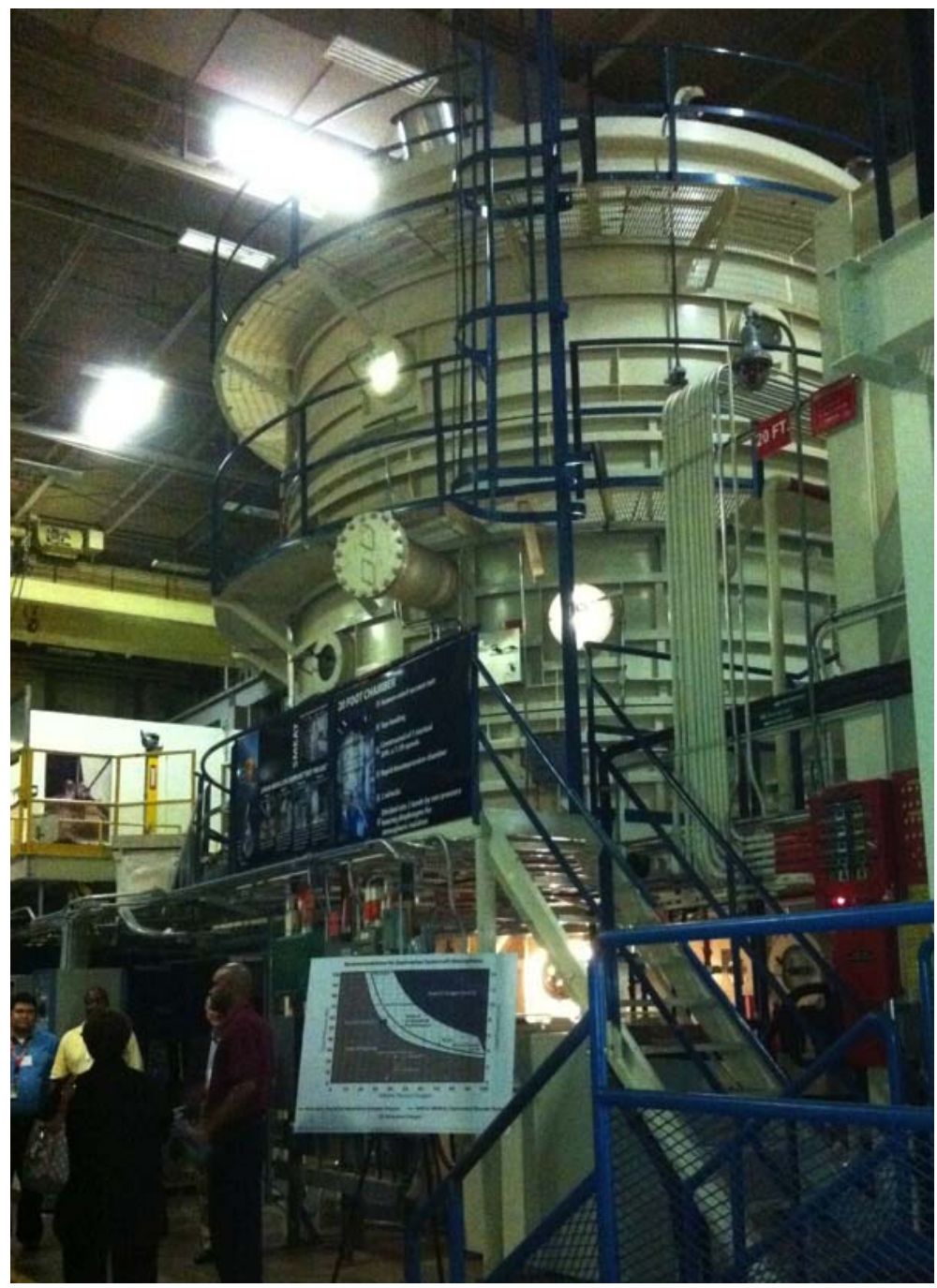




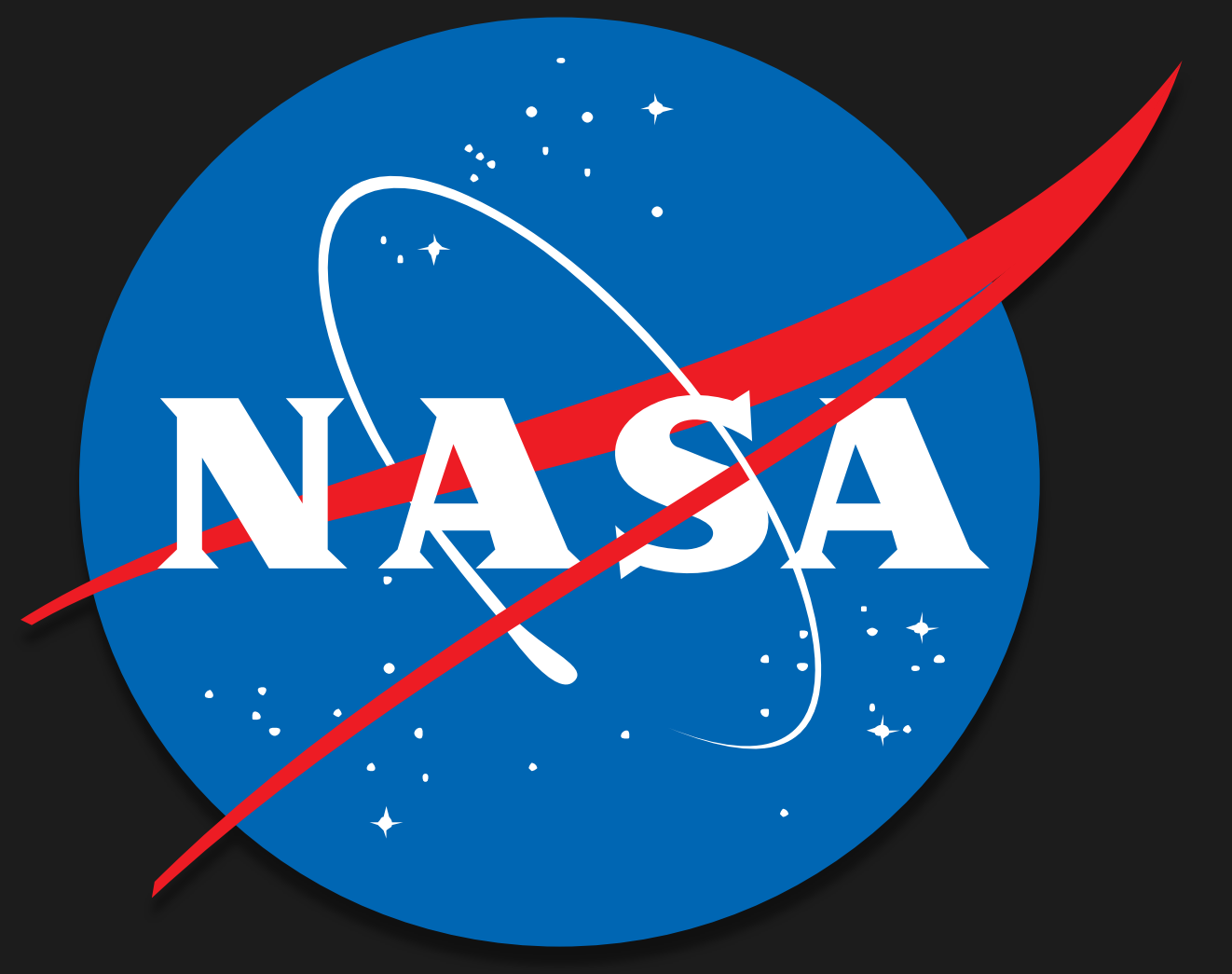

